\title{
Satellite Images of Warm Core Ring 82-B \\ Sea Surface Temperature and a Chronological Record of Major Physical Events Affecting Ring Structure
}

Woods Hole rceanographic Institution ATLAS - GAZETTEER COLLECTION by

PLEASE RETURN
TO
INTSTITUTION DATA LIBRARY
MCLEAN

\section{R. Evans $^{1}$, K. Baker ${ }^{2}$, O. Brown ${ }^{1}$, \\ R. Smith ${ }^{3}$, S. Hooker', D. Ol.son 1 \\ and}

\footnotetext{
${ }^{1}$ Division of Meteorology and Physical Oceanography Rosenstiel School of Marine and Atmospheric Science University of Miami
}

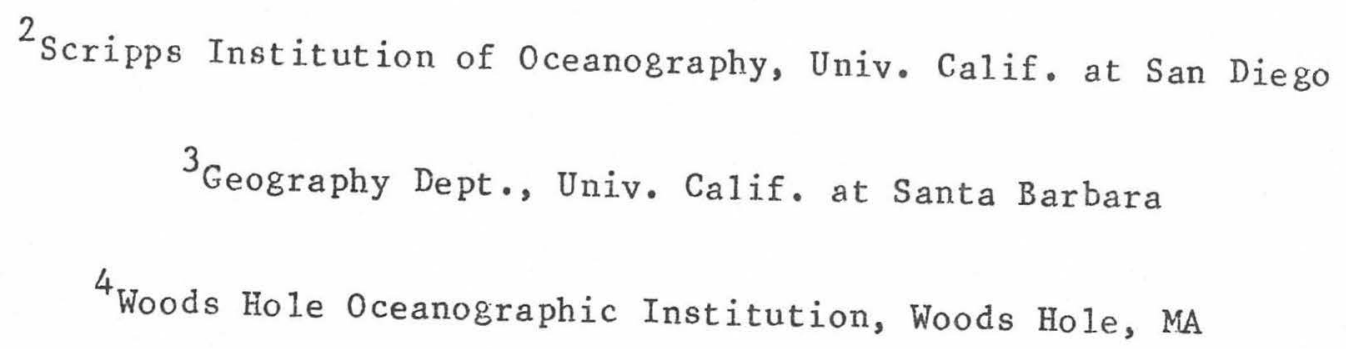


A chronology constructed from satellite-derived thermal imagery is presented to describe the formation and life history of warm-core ring 82-B. A comparison is made with warm-core ring $81-\mathrm{F}$ in order to illustrate similarities that may be common to warm-core rings that traverse the region of the Slope Water occupied by $82-\mathrm{B}$. Particular attention is paid to discrete events identified from analysis of changes in the surface therma 1 field. Significant events include interactions between the ring and the Gulf Stream, warm (Gulf Stream) and cold (shelf) streamers and interaction with other vortices. The events are documented by following changes in ring size, shape, translation, and surface thermal structure. Observations determined from the infrared satellite imagery are supported by hydrography, acoustic velocity profiling and drifter trajectories.

Please refer to Appendix IV, Ring Glossary, for definitions of ring terminology.

Introduction

As part of the Warm-Core Rings Experiment, satellite imagery was acquired by University of Miami investigators for the purpose of studying warm-core ring 82-B during 1982. These data provide a unique daily synoptic view of mesoscale thermal variability on scales of $1-1000 \mathrm{Km}$ and serve as a basis for a number of kinematical studies of ring behavior and evolution. The present volume is a compendium of cloud-free satellite images for the 1 ifetime of ring $82-B$ which were received from the polar orbiting spacecraft NOAA-7 using the Advanced Very High Resolution Radiometer (AVHRR).

The AVHRR observes space-going radiation in two visible bands $(550-680$ nm., 725-1100 nm.) and three infrared bands $(3.55-3.93 \mu \mathrm{m}, 10.3-11.3 \mu \mathrm{m}$, 
11.5-12.5 $\mu \mathrm{m})$. A standard processing procedure is used to transform the raw satellite sensed radiances to a gridded temperature image. This procedure includes navigation wherein each satellite picture element is earth located to within one kilometer. Radiance data are atmospherically corrected using a two-channel (10.3-11.3 $\mu \mathrm{m}$ and 11.5-12.5 $\mu \mathrm{m})$ algorithm that corrects for water vapor and optical path length effects. The atmospherically corrected image is then remapped onto a pseudomercator projection. Sea surface temperatures processed in this manner have a nominal $0.7 \mathrm{C}$ rms scatter. A bias term ranging from 0 to $0.75 \mathrm{C}$ can also be present which may have diurnal and seasonal components. This bias tends to affect large areas of an image and can be corrected in a number of ways (McClain, 1981; Bernstein, 1983). The final image is scaled from $0 \mathrm{C}$ to $29 \mathrm{C}$ in $0.125 \mathrm{C}$ steps and covers an area from $34.95 \mathrm{~N}$ to $40.05 \mathrm{~N}$ and $69.70 \mathrm{~W}$ to $76.30 \mathrm{~W}$ in one kilometer increments. The original data set includes an average of two images per day from Julian Day (day) 50 through the end of 1982 plus selected days prior to day 50. Images have been analyzed through day 241; the resulting data set contains 145 useable images.

The thermal images presented in this volume are color enhanced in $1 \mathrm{C}$ steps to show areal relations and seasonal changes in temperature. A separate enhancement (not shown) is used to highlight temperature gradients which facilitates the analysis of individual features and the location of frontal boundaries.

Analysis of satellite images of temperature and chlorophyll is an evolving process. Detecting a ring's presence is staightforward if sufficient temperature contrast is present. Determination of ring center, however, is complicated by the detailed and constantly evolving structure of the surface 
signature. Warm-core rings exhibit a warm central core that is usual1y surrounded by streamers which may be warm, cold, or a combination of both. Previous estimates of ring center from satel lite imagery utilized the thermal contrast associated with the boundary of the high velocity region (Brown et a1., 1983). Subsequent analysis showed that a center determined in this manner has approximately a 5 kilometer rms noise associated with it and is sensitive to forcing that can alter the apparent location of the high temperature front (e.g., frontal wave motion, vortices imbedded in an entrainment region, and Gulf Stream encounters). The present approach utilizes the entrainment field with successive center estimates produced by analyzing different entrainment boundaries and incorporating center estimates from temporal1y neighboring images to produce a smooth track and stable size estimates. Figure 1, presented on panel 3, shows 82-B's track relative to the bottom topography highlighted by letters adjacent to major event locations. A table of the resulting ring center positions and related information is given in an appendix with a Julian to Gregorian calendar to aid in matching images and following this description; the event relations are depicted in Figure 2. The new center estimates have been compared to the previous analysis and are found to agree well with the derived track line and earlier XBT and drifter derived center estimates (Hooker and 01 son, 1984). Consequent $1 y$, modifications to the ring trajectory are restricted to intercruise periods.

In most cases when the ring is free of external forcing, such as Gulf Stream or vortex interaction, central core determined centers agree with those produced from analysis of the entrainment field. A major difference lies in the image-derived size estimates. Normal1y, the high temperature core tends 
to coincide with the radius to the velocity maximum ( $\left.\mathrm{R}_{\mathrm{vmax}}\right)$. Utilizing the entrainment field produces a size estimate that is approximately 15 kilometers larger than the $\mathrm{R}_{\text {vmax }}$ A problem associated with entrainment location is estimation of where a specified streamline lies relative to the changing temperature of the entrainment feature for different ring quadrants. At present this problem is minimized by analyzing images in sets and imposing continuity requirements on feature selection.

Overview

Warm-core ring 82-B formed from a Gulf Stream meander sometime after day 39 and is first observed as a detached ring on day 56 with a surface core temperature between 18 and $18.5 \mathrm{C}$. Separation probably occurs close to the day 39 observation; lack of clear satelite imagery prevents more accurate estimation of the formation date and initial surface temperature. Cooling is observed as a steady decrease in ring central core temperature between days 59 and 95 (0.03 - $0.04 \mathrm{C} /$ day). Central core area shrinks between days 85 and 95 when cooler shelf and Slope Water is observed to penetrate the high velocity region. Ring $82-\mathrm{B}$ abrupt $1 \mathrm{y}$ cools to $15.9 \mathrm{C}$ following the passage of a major storm during days 96-97. Surface temperature remains nearly constant until day 136 when warming suggests cessation of deep convection. After a period of continuous cloudiness, $82-B$ is observed to have warmed, presumably from entrainment of a warm Gulf Stream streamer. Ring cooling resumes and is aided by entrainment of cold shelf streamers through day 166. After passage of a storm on day $169,82-$ B begins an uninterrupted seasonal warming that lasts until day 180. Surface temperature from this point through the end of the series on day 241 is moderated by a series of Gulf 
Stream interactions and streamer events. Appendix I summarizes the history of $82-$ B.

Image Discussion

Ring 82-B forms from a northward flowing Gulf Stream meander situated along the $70 \mathrm{~W}$ meridian to $38.5 \mathrm{~N}$ (Figure 1, position $\mathrm{A}$ ). Interaction with warm-core ring $81-\mathrm{F}$, 1ocated northeast of the meander at $70.6 \mathrm{~W}, 39.3 \mathrm{~N}$, from day 29 to 39 probably assists in the formation process. A gap in available imagery prevents observation of the separation sequence; however, $82-B$ is observed to be separated from the Gulf Stream and advecting shelf water into the Slope Water by day 56. Rings $81-\mathrm{F}$ and $82-\mathrm{B}$ remain in close proximity with their high velocity regions separated at times by as 1 ittle as $15 \mathrm{Km}$ while $81-F$ transits the Hudson Canyon area. Both $81-F$ and $82-B$ rapidly evolve between days 70 and 90 . A small cyclone-anticyclone pair forms between the two rings. The small cyclone is advected by the $81-\mathrm{F}$ flow field, and by day 77 its surface expression becomes entrained into 81-F. Absorption of an associated cyclone carrying a mixture of shelf and slope Water in its surface layers can rapid1y alter a ring's characteristics. In this case, absorption causes a covering of approximately $40 \%$ of the ring's surface area with cooler water. Surface advection associated with this event rapidy cools the ring and distorts the surface temperature pattern. Ring $81-F$ is again recognizable as an anticyclonic circulation by day 90 with a surface temperature characteristic of the surrounding Slope Water. A similar ring-cyclone interaction is observed as $82-\mathrm{B}$ passes the Hudson Canyon although 82-B does not absorb the cyclone. Ring 82-B survives a near Gulf Stream encounter when a meander passes within 15-30 km of the high velocity region on days 71 to 82 (Figure 1, position B). Cooling by 
entrainment of cooler Slope Water and shelf water is evident starting from days 75 to 85 and lasting through day 95 as evidenced by shrinkage of the centra1 warm surface pool (Figure 1, position C). Passage of the aforementioned storm during days 96-97 1owers ring surface temperature to the level observed during the April cruise.

During the time interval from formation until interaction with the Hudson Canyon fan, $82-B$ translates to the west along the $2700 \mathrm{~m}$ isobath at approximately $4 \mathrm{~cm} / \mathrm{sec}$ until day 91 (see Figure 1) whereupon it veers to the southwest through day 109. Streamer activity during the westward passage is characterized by cold streamers. No significant Gulf Stream meanders are observed from day 90 to 109. Interaction with the Hudson Canyon spans the period from days 109 to 123 when water depth under ring center decreases to $2400 \mathrm{~m}$ (Figure 1, position D). At this time ring ellipticity increases, and a warm streamer is observed. As a consequence of the topographic interaction, the ring's major axis orientation shifts from essentially north-south to eastwest. During the same period, associated cyclonic vortices are observed to the north, east, and south of 82-B. A warm streamer that begins on day 109 reaches the western side of $82-\mathrm{B}$ by day 115 , detaches from ring influence, and is advected to the southwest as a linear cross slope feature showing nearly uniform drift to the southeast.

Interaction with an associated cyclone dominates the period from day 123 to day 132 as 82-B moves downslope from the Hudson Canyon fan. A cyclone that forms on the northeast of $82-B$ is advected to a position east of the warm ring in a sequence similar to that affecting $81-\mathrm{F}$. Although $82-\mathrm{B}$ does not absorb the cyclone, shelf water entrainment is enhanced. Cyclone aided entrainment continues from 132 to 139, whereupon the first spiral of cooler water into 
ring center is observed. The ring returns to a track following the $2800 \mathrm{~m}$ isobath, and translation speed increases to approximately $7 \mathrm{~cm} / \mathrm{s}$ (Figure 1 , position E). The increased velocity is mostly in the meridional component. Ring $81-\mathrm{F}$ is involved in a series of Gulf Stream encounters from day 125 onward; subsequent1y, Gulf Stream meander amplitude is observed to increase. A Gulf Stream meander approaches $82-\mathrm{B}$ on day 139. Fo11owing an intervening cloudy period that lasts until day $146,82-B$ is observed to be significantly warmer suggesting a warm streamer event has overridden the surface layer (Figure 1, position F).

Ring 82-B begins a period of Gulf Stream and topographic interactions following day 153 when a near Gulf Stream encounter occurs and ring center returns to the $2400 \mathrm{~m}$ isobath (Figure 1, position G). A similar event progression is observed spanning days 160 to 168 when a cyclone appears on the northern ring boundary and is advected around the high velocity region to the east. This cyclone interaction preceeds a period of cold entrainment that penetrates to the ring interior (Figure 1 , position $\mathrm{H}$ ).

A major storm passes over 82-B on day 169 erasing smal1 scale horizontal structure and entrainment features. Ring $82-B$ becomes nearly stationary after day 175 when it reaches a point bounded by the Gulf Stream to the south and topography to the west; subsequent ring translation is dominated by Gulf Stream behavior. A prominent cold streamer is evident on days 174 and 175 when shelf water is advected across the Slope Water to the Gulf Stream where it continues downstream. Another consequence of the ring's arrival at this position relative to the Gulf Stream is the appearance of a cyclone to the southwest of the ring and generation of pronounced warm streamers (days 177 to 180). 
Strong interactions between the ring and the Gulf Stream, where Gulf Stream water displaces ring surface and upper core water, are frequently seen from this time onward. The first such event is centered on day 183 when ring surface temperature increases as Gulf Stream water is introduced into the surface layer. The characteristic near circular ring temperature surface expression is perturbed during an overwash event. The surface manifestation of the ring is disturbed by this overwash from days 183 to 189 . Ring 1ocation changes markedly during such encounters as the ring moves rapidly to the northeast and then returns to the southwest following the passage of the meander. Encounters between the ring and the Gulf Stream are centered on days 183, 202, 218, 222, and 238 (Figure 1, position I). Rapid surface warming of the $\mathrm{S}$ lope and shelf waters through day 199 reduces therma 1 contrast between 82-B and its surrounding environment. The ring boundary becomes more evident on days 203 and 206 as Gulf Stream water is entrained by the ring during a meander encounter. The ring boundary remains in close proximity to the north wall of the Gulf Stream through day 222 when $82-B$ experiences a major overwash event. On day 228, the ring is displaced to the north and is reduced in size. Ring 82-B resumes translation to the southwest and encounters the Gulf Stream north wall by day 238. Ring surface thermal expression remains indistinct through the end of the time series on day 241. 
Acknowledgments

The authors would like to acknowledge the work of Messrs. James Brown, Steve Emmerson and Angel Li in the computer software and navigation generation. We particularly wish to acknowledge the other Warm-Core Rings Experiment investigators for their many insightful comments and encouragement. Data for this analysis were obtained through the special efforts of NOAA NESDIS Operations and Research Groups (AVHRR) and NASA GSFC NIMBUS Project (czCs). The present work could not have been accomplished without their joint efforts; the authors wish to thank these groups for their support.

This research is part of the Warm-Core Rings Experiment; support of the Miami investigators by the National Science Foundation under grant NSF-OCE-8016991, the Office of Naval Research under contract N000-80-C-0042, and the National Aeronautics and Space Administration under contract NAGW-273 is gratefully acknowledged. Support of the UCMBO University of California investigators by NASA under contract NAG6-14 and support of the Warm-Core Rings Program Service Office at Woods Hole Oceanographic Institution through the National Science Foundation Grant NSF-OCE-80-17248 is al so gratefully acknowledged. 


\section{References}

Bernstein, R.L. 1983. Sea surface temperature estimation using the NOAA 6 satel1ite Advanced Very High Resolution Radiometer. J. Geophys. Res., $87(\mathrm{cl} 2): 9455-9465$.

Brown, O.B., D.B. 01 son, J.W. Brown and R.H. Fvans. 1983. Satel1ite infrared observation of the kinematics of a warm-core ring. Aust. J. Mar. Freshw. Res., 34: 535-545.

Hooker, S.B. and D.B. 01son. 1984. Center of mass estimation in closed vortices: A verification in principle and practice. Submitted to $\mathrm{J}$. Atmos. Ocean Tech.

McClain, E.P. 1981. Multiple Atmospheric-Window Techniques for Satellite Sea Surface Temperatures. In: Oceanography From Space. J.F.R. Gower, ed. Plenum Press, pp. 73-85. 
Figure 2.

82-B EVENT CHRONOLOGY

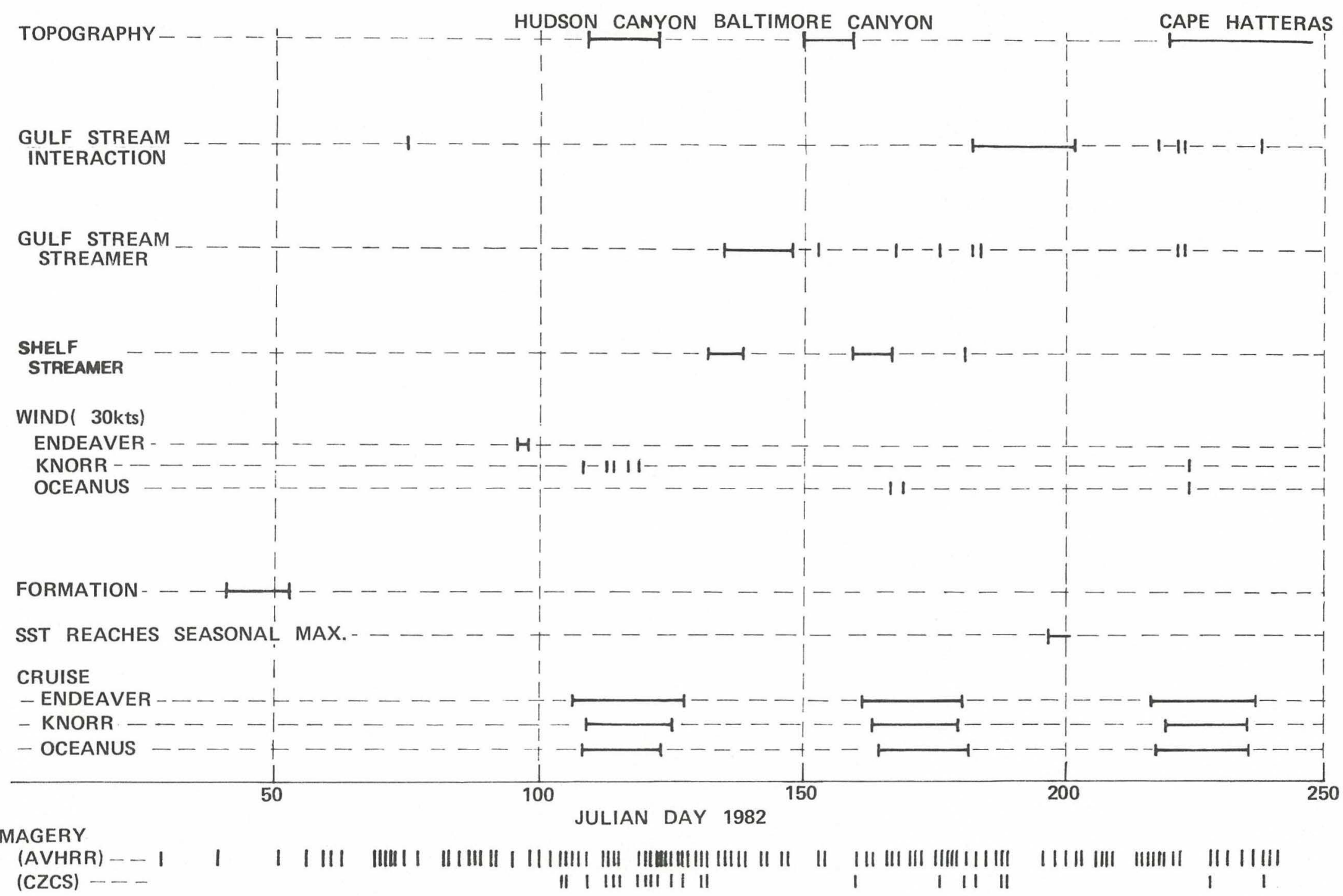




\section{APPENDIX I}

Table 1

Ring 82-B Center Location

\begin{tabular}{|c|c|c|c|c|c|c|}
\hline $\begin{array}{l}\text { Lon } \\
\text { W }\end{array}$ & $\begin{array}{c}\text { Lat } \\
\mathrm{N}\end{array}$ & $\begin{array}{l}\text { Julian } \\
\text { Day }\end{array}$ & & & $\begin{array}{l}\text { Phase } \\
\text { deg T }\end{array}$ & Comments \\
\hline$\overline{69.41}$ & $\overline{38.49}$ & 39 & 80 & 64 & 313 & 82-B formation \\
\hline 69.58 & 39.11 & 56 & 90 & 62 & 17 & ring to west at $4 \mathrm{~cm} / \mathrm{sec}$ \\
\hline 69.71 & 39.10 & 59 & 84 & 68 & 53 & 1 \\
\hline 69.68 & 39.10 & 61 & 84 & 76 & 52 & water depth $2700 \mathrm{~m}$ \\
\hline 69.74 & 39.10 & 63 & 82 & 74 & 29 & \\
\hline 70.06 & 39.09 & 71 & 80 & 80 & 18 & \\
\hline 70.09 & 39.10 & 73 & 76 & 71 & 335 & \\
\hline 70.15 & 39.09 & 74 & 81 & 70 & 356 & \\
\hline 70.37 & 39.17 & 77 & 80 & 73 & 13 & \\
\hline 70.56 & 39.17 & 82 & 85 & 69 & 20 & \\
\hline 70.64 & 39.17 & 85 & 78 & 71 & 349 & \\
\hline 70.81 & 39.15 & 88 & 76 & 67 & 34 & \\
\hline 70.81 & 39.16 & 89 & 78 & 68 & 34 & \\
\hline 70.88 & 39.13 & 91 & 85 & 74 & 29 & $\underset{V}{ }$ \\
\hline 70.87 & 39.13 & 92 & 83 & 71 & 49 & ring to sw @ 232 \\
\hline 71.13 & 39.06 & 95 & 82 & 58 & 53 & \\
\hline & & & & & & {$\left[\begin{array}{ll}96-97 & \text { major storm over } 82-B \\
99-100 & \text { storm to east of } 82-B\end{array}\right.$} \\
\hline 71.08 & 39.05 & 102 & 73 & 64 & 308 & \\
\hline 71.09 & 39.07 & 105 & 76 & 67 & 297 & \\
\hline 71.05 & 39.06 & 107 & 77 & 63 & 321 & $\underline{V}$ \\
\hline 71.25 & 38.95 & 109 & 83 & 59 & 342 & Hudson Canyon interaction \\
\hline 71.22 & 38.93 & 110 & 74 & 60 & 349 & \\
\hline 71.42 & 38.92 & 113 & 86 & 67 & 27 & ring to west then reverse \\
\hline 71.55 & 38.90 & 114 & 81 & 60 & 41 & back to east \\
\hline 71.57 & 38.88 & 115 & 91 & 59 & 49 & water depth $2700_{\mathrm{m}}$ to $2400_{\mathrm{m}}$ \\
\hline 71.89 & 38.91 & 119 & 96 & 55 & 68 & \\
\hline 71.71 & 38.91 & 121 & 92 & 50 & 85 & \\
\hline 71.65 & 38.83 & 123 & 78 & 58 & 282 & $\underline{V}$ \\
\hline 71.63 & 38.76 & 124 & 85 & 62 & 290 & cyclone dominated streamer \\
\hline 71.56 & 38.84 & 125 & 82 & 64 & 80 & \\
\hline 71.69 & 38.76 & 127 & 77 & 63 & 290 & $\downarrow$ \\
\hline 71.89 & 38.57 & 132 & 80 & 69 & 288 & ring to $\mathrm{sw}$ at $7 \mathrm{~cm} / \mathrm{sec}$ \\
\hline 71.96 & 38.46 & 135 & 80 & 64 & 325 & water depth $2800_{\mathrm{m}}$ \\
\hline 72.01 & 38.40 & 136 & 81 & 66 & 331 & \\
\hline 72.06 & 38.41 & 138 & 85 & 69 & 345 & \\
\hline 72.08 & 38.39 & 139 & 85 & 72 & 342 & \\
\hline 72.42 & 38.29 & 147 & 84 & 71 & 57 & \\
\hline 72.88 & 37.89 & 153 & 82 & 75 & 272 & \\
\hline 72.90 & 37.87 & 154 & 84 & 76 & 56 & depth shallows to $2400_{\mathrm{m}}$ \\
\hline 73.27 & 37.66 & 160 & 77 & 67 & 76 & $\downarrow$ \\
\hline
\end{tabular}


Table 1. (continued)

\begin{tabular}{|c|c|c|c|c|c|c|}
\hline $\begin{array}{c}\text { Lon } \\
W\end{array}$ & $\begin{array}{c}\text { Lat } \\
\mathrm{N}\end{array}$ & $\begin{array}{c}\text { Julian } \\
\text { Day }\end{array}$ & \multicolumn{2}{|c|}{$\begin{array}{c}\text { Size } \\
\mathrm{K}_{\mathrm{m}}\end{array}$} & $\begin{array}{l}\text { Phase } \\
\text { deg T }\end{array}$ & Comments \\
\hline 73.57 & $\overline{37.22}$ & 166 & $\overline{74}$ & 63 & 272 & 1 \\
\hline 73.62 & 37.18 & 167 & 76 & 64 & 49 & \\
\hline 7390 & $36 \quad 95$ & 175 & 71 & 52 & 344 & $\sqrt{169}$ major storm over $82-B$ \\
\hline $\begin{array}{l}73.90 \\
73.91\end{array}$ & $\begin{array}{l}30.95 \\
36.92\end{array}$ & $\begin{array}{l}175 \\
176\end{array}$ & $\begin{array}{l}11 \\
78\end{array}$ & 47 & 343 & $\frac{-}{\text { start of series of } \mathrm{GS}}$ \\
\hline 73.91 & 36.93 & 177 & 65 & 50 & 341 & interactions \\
\hline 73.91 & 36.85 & 178 & 58 & 55 & 56 & \\
\hline 73.81 & 36.85 & 180 & 58 & 51 & 297 & \\
\hline 73.86 & 36.77 & 181 & 73 & 51 & 271 & \\
\hline 73.96 & 36.86 & 187 & 70 & 56 & 313 & \\
\hline 73.98 & 36.84 & 188 & 68 & 66 & 76 & \\
\hline 73.96 & 36.86 & 189 & 68 & 61 & 67 & \\
\hline 73.49 & 36.80 & 198 & 73 & 54 & 86 & \\
\hline 73.56 & 36.89 & 200 & 66 & 50 & 297 & \\
\hline 73.75 & 36.92 & 203 & 64 & 32 & 296 & Gulf Stream interaction \\
\hline 73.82 & 36.88 & 206 & 54 & 44 & 306 & \\
\hline 73.70 & 36.89 & 207 & 55 & 37 & 301 & \\
\hline 73.96 & 36.60 & 214 & 46 & 42 & 73 & \\
\hline 74.00 & 36.61 & 215 & 60 & 47 & 43 & \\
\hline 74.02 & 36.51 & 216 & 64 & 53 & 40 & \\
\hline 74.10 & 36.53 & 218 & 58 & 41 & 59 & Gulf Stream interaction \\
\hline 73.94 & 36.61 & 221 & 44 & 33 & 64 & \\
\hline 73.86 & 36.47 & 222 & 49 & 42 & 295 & Gulf Stream interaction \\
\hline 74.09 & 36.95 & 228 & 40 & 32 & 338 & \\
\hline 74.13 & 36.76 & 229 & 45 & 28 & 11 & \\
\hline 74.37 & 36.69 & 234 & 48 & 33 & 66 & \\
\hline 74.26 & 36.47 & 238 & 41 & 33 & 89 & Gulf Stream interaction \\
\hline 74.32 & 36.46 & 239 & 44 & 33 & 69 & \\
\hline
\end{tabular}




\section{APPENDIX II}

Table 2.

Julian to Gregorian Calendar (1982)

Jan Feb Mar Apr May Jun Jul Aug Sep Oct Nov Dec

Day

$\begin{array}{rrrrrrrrrrrrr}1 & 1 & 32 & 60 & 91 & 121 & 152 & 182 & 213 & 244 & 274 & 305 & 335 \\ 2 & 2 & 33 & 61 & 92 & 122 & 153 & 183 & 214 & 245 & 275 & 306 & 336 \\ 3 & 3 & 34 & 62 & 93 & 123 & 154 & 184 & 215 & 246 & 276 & 307 & 337 \\ 4 & 4 & 35 & 63 & 94 & 124 & 155 & 185 & 216 & 247 & 277 & 308 & 338 \\ 5 & 5 & 36 & 64 & 95 & 125 & 156 & 186 & 217 & 248 & 278 & 309 & 339 \\ 6 & 6 & 37 & 65 & 96 & 126 & 157 & 187 & 218 & 249 & 279 & 310 & 340 \\ 7 & 7 & 38 & 66 & 97 & 127 & 158 & 188 & 219 & 250 & 280 & 311 & 341 \\ 8 & 8 & 39 & 67 & 98 & 128 & 159 & 189 & 220 & 251 & 281 & 312 & 342 \\ 9 & 9 & 40 & 68 & 99 & 129 & 160 & 190 & 221 & 252 & 282 & 313 & 343 \\ 10 & 10 & 41 & 69 & 100 & 130 & 161 & 191 & 222 & 253 & 283 & 314 & 344 \\ 11 & 11 & 42 & 70 & 101 & 131 & 162 & 192 & 223 & 254 & 284 & 315 & 345 \\ 12 & 12 & 43 & 71 & 102 & 132 & 163 & 193 & 224 & 255 & 285 & 316 & 346 \\ 13 & 13 & 44 & 72 & 103 & 133 & 164 & 194 & 225 & 256 & 286 & 317 & 347 \\ 14 & 14 & 45 & 73 & 104 & 134 & 165 & 195 & 226 & 257 & 287 & 318 & 348 \\ 15 & 15 & 46 & 74 & 105 & 135 & 166 & 196 & 227 & 258 & 288 & 319 & 349 \\ 16 & 16 & 47 & 75 & 106 & 136 & 167 & 197 & 228 & 259 & 289 & 320 & 350 \\ 17 & 17 & 48 & 76 & 107 & 137 & 168 & 198 & 229 & 260 & 290 & 321 & 351 \\ 18 & 18 & 49 & 77 & 108 & 138 & 169 & 199 & 230 & 261 & 291 & 322 & 352 \\ 19 & 19 & 50 & 78 & 109 & 139 & 170 & 200 & 231 & 262 & 292 & 323 & 353 \\ 20 & 20 & 51 & 79 & 110 & 140 & 171 & 201 & 232 & 263 & 293 & 324 & 354 \\ 21 & 21 & 52 & 80 & 111 & 141 & 172 & 202 & 233 & 264 & 294 & 325 & 355 \\ 22 & 22 & 53 & 81 & 112 & 142 & 173 & 203 & 234 & 265 & 295 & 326 & 356 \\ 23 & 23 & 54 & 82 & 113 & 143 & 174 & 204 & 235 & 266 & 296 & 327 & 357 \\ 24 & 24 & 55 & 83 & 114 & 144 & 175 & 205 & 236 & 267 & 297 & 328 & 358 \\ 25 & 25 & 56 & 84 & 115 & 145 & 176 & 206 & 237 & 268 & 298 & 329 & 359 \\ 26 & 26 & 57 & 85 & 116 & 146 & 177 & 207 & 238 & 269 & 299 & 330 & 360 \\ 27 & 27 & 58 & 86 & 117 & 147 & 178 & 208 & 239 & 270 & 300 & 331 & 361 \\ 28 & 28 & 59 & 87 & 118 & 148 & 179 & 209 & 240 & 271 & 301 & 332 & 362 \\ 29 & 29 & & 88 & 119 & 149 & 180 & 210 & 241 & 272 & 302 & 333 & 363 \\ 30 & 30 & & 89 & 120 & 150 & 181 & 211 & 242 & 273 & 303 & 334 & 364 \\ 31 & 31 & & 90 & & 151 & & 212 & 243 & & 304 & & 365\end{array}$


APPENDIX III

\section{A Note on Interpretation of Satellite Therma1 Images}

Sea surface temperatures are computed using a two-channel algorithm to correct for variable concentrations of atmospheric water vapor (McClain, 1981). The resulting temperature field is mapped to a 500 by $500 \mathrm{~km}$ pseudomercator grid with a nominal satellite ground resolution of $1 \mathrm{~km}$. When the atmospheric conditions are within the correction capabilities of the twochannel algorithm, sea surface temperature is computed with an rms error of $0.75 \mathrm{C}$ and is represented in the color images as $1 \mathrm{C}$ color steps with purple and blue representing cold temperature, green and yellow, mid-range, and orange and red, warm. Due to the change in ring geographical location with time, images are centered at $70.5 \mathrm{~W}, 38 \mathrm{~N}$ from February through March, and $73.5 \mathrm{~W}, 37 \mathrm{~N}$ from April through August. Location reference is provided by a $30 \times 30$ navigation grid and an overlay of the $200 \mathrm{~m}$ isobath. Continental 1 and masses are highlighted in brown. Features in the first three images, days 29, 39, and 50, are used to describe some aspects of image interpretation.

Day 29 is representative of ocean structure resolvable in thermal imagery on a clear, dry day. Features to note in the image: The Gulf stream is the yellow-orange feature; extending northward along $70 \mathrm{~W}$ is the meander which forms ring 82-B; the green elipitical feature centered at $71 \mathrm{~W}, 39 \mathrm{~N}$ is ring 81-F; and the dark blue linear feature immediately to the east of $81-F$ is a cold shelf streamer. The Slope Water region appears light blue between the warmer (yellow) Gulf Stream and the colder (dark blue) shelf waters. The blue speckled region on the eastern side of the Gulf Stream is indicative of sma 11 clouds. Increased cloudiness is seen on the eastern side of the image on day 39. An area covered by clouds, haze or fog, is harder to estimate 
when the obscuring element has an apparent temperature similar to that of the surrounding water. Analysis of adjacent temporal images for space scales consistent with oceanographic structure can be used to aid in resolving indistinct cloud boundaries. The slanted dark lines seen south of $37 \mathrm{~N}$ are areas of no data. Dark areas seen on day 50 are clouds. The colored areas surrounding the obvious cloudy areas are atmospheric transition regions where the sea surface remains obscured but where temperatures are computed that could represent realistic ocean surface temperatures. 
APPENDIX IV

\section{RING GLOSSARY}

Absolute vorticity: The sum of the relative vorticity plus the planetary vorticity. (See potential vorticity for importance and use.)

Advanced Very High Resolution Radiometer (AVHRR): $\nabla$ isible and infrared sensing radiometer carried on TIROS-N/NOAA-6/7/8 satellites. Views the earth in two visible channels $(400-700 \mathrm{~nm}, 800-1100 \mathrm{~nm})$ and three infrared bands $(3.7-4.2 \mu \mathrm{m}, 10-11 \mu \mathrm{m}, 11-12 \mu \mathrm{m})$.

Advection: The moving of a fluid parcel as a result of the velocity field of the fluid.

Anticyclogenesis: The strong shrinking of a fluid column which leads to an increase in negative relative vorticity. This can cause the spinning up of a warm-core ring or the spinning down of a cold-core ring.

Anticyclonic: Motion against the direction of the earth's rotation, clockwise in the northern hemisphere.

Attenuation Length (meters-1): (1) The reciprocal of the total attenuation coefficient (the sum of the total absorption and scattering coefficients). (2) Loosely, the reciprocal of the diffuse attenuation coefficient for total or scalar irradiance. For consistency in biological and CZCS applications, it is useful to consider the total diffuse attenuation of photosynthetic available radiation (PAR) as measured using a quantum scalar irradiance meter (Kpar) and to take the "attenuation length" as $(\mathrm{K} \text { par })^{-1}$.

Available potential energy ( $A P E$ ): The energy available for conversion to kinetic energy due to the relaxation of the pressure field back to the far field reference. In the case of a ring, this is the energy gained in flattening the thermal field into the slope Water; i.e., adding the ring core to the Slope Water. (see Pedlosky, 1979; Reid et a1., 1981)

AVHRR: See Advanced Very High Resolution Radiometer.

Chlorophyl1 (surface): (1) The concentration of chlorophyll measured in a water sample, usually within the top few meters of the water column. (2) In a short quantitative sense, the signal measured by the satellite sensor is determined by the spectral absorption and backscattering properties of the water. These properties, in turn, are primarily due to chlorophy 11 and phaeopigments (in biogenous waters) appropriately integrated to a depth of one attenuation length (a depth corresponding to $22 \%$ of the euphotic depth). Thus, "surface chlorophy 11 " as determined by satellite, is a sum of chlorophyll and phaeophytin integrated over a significant fraction of the euphotic zone (Gordon and McCluney, 1975; Smith, Baker, and Dustan, 1981; and Smith, 1981). (3) Loosely, and when discussing along-track fluorescence determination of chlorophyl1, the chlorophyl1 concentration at the depth of the ship's seawater intake. 
In general, there is a strong correlation between the surface values of chlorophyll and the value integrated to one attenuation length (Smith and Baker, 1978).

Coastal Zone Color Scanner (CZCS): Visible/infrared radiometer carried on NIMBUS-7 spacecraft for the sensing of ocean color. Views the earth in the visible and near infrared (5 channels: $443 \mathrm{~mm}, 520 \mathrm{~nm}_{0}, 550 \mathrm{~nm}, 670$ nm., $750 \mathrm{~nm}$ ) and the infrared (1 channe 1: $9.6-12 \mathrm{um}$ ).

Cold wall (of the Gulf Stream): See north wall.

Compensation depth: Depth at which photosynthesis is equal to respiration in the phytoplankton.

Cyclogenesis: The strong stretching of a fluid column which leads to an increase in positive relative vorticity. This can cause the spinning down of a warm-core ring or the spinning up of a cold-core ring.

Cyclonic: Motion in the direction of the earth's rotation, counterclockwise in the northern hemisphere.

CZCS: See Coastal Zone Color Scanner.

Deformation radius: See Rossby deformation radius.

Detrainment: The expulsion of fluid out of a feature by advection (See diffusion for a clarification of the difference between the scales involved.)

Diffusion: The flux of fluid properties down-gradients by subscale processes (molecular in the most simple case). (See turbulent diffusion for a further comparison.)

Dissipation: The thermodynamically irreversible conversion of the state of a property, as for example, the conversion of kinetic energy into heat.

Eccentricity ( ): A measure of the ellipticity of a feature. Defined as: $\left(a^{2}-b^{2}\right) / a$, where $a$ is the major axis and $b$ is the minor axis of the ellipse.

Eddy: See vortex.

Eddy Diffusivity: A proportionality coefficient relating the down-gradient turbulent flux of a property to the mean gradient of that property. Eddy diffusivity is not a universal constant, but rather depends substantially on the properties of the flow.

Eddy Viscosity: A proportionality constant relating the down-gradient flux of momentum to the shear (velocity gradient). Because velocity is not a passive property, the eddy viscosity is different (apparently larger) from the eddy diffusivity. 
Entraiment: The incorporation of fluid into a feature by advection. (See diffusion for a clarification of the difference between the scales involved.)

Euphotic depth: Optically, the depth to which irradiance is reduced to $1 \%$ of its surface value. As a rough rule, the euphotic depth is equivalent to 4.6 attenuation lengths (Parsons, Takahashi, and Hargrave, 1977).

Front: A gradient zone caused by horizontal convergence of two fluids of differing densities associated with an upward velocity shear. These features also lead to sharp gradients in other fluid properties.

Gradient: The change of a property with respect to a spatial interval.

Gulf Stream core: Defined as the $15 \mathrm{C}$ isotherm at $200 \mathrm{~m}$ (Stomme1, 1966). This is typically associated with an advective plume of warm surface waters and the maximum surface velocity.

High velocity region: That part of a ring associated with the region of swiftly moving Gulf Stream water. This is typically in the area of the maximum thermostad volume per unit radius and just inside the surface ring front.

Intrusion: A fine scale (less than $10 \mathrm{~km}$ in horizontal dimensions and less than $100 \mathrm{~m}$ in the vertical) entrainment of fluid often associated with thermohaline effects, such as, double diffusion.

Rinetic energy (KE): The energy associated with the velocity field of a feature.

Meander: A large scale, deformation radius or larger (greater than 50 kilometers), wave in a front or current.

Mixed layer: A layer within which fluid properties have constant thermodynamic values. For example, a completely mixed layer has a zero vertical potential density gradient.

Mixing: The thermodynamically irreversible molecular diffusion of a fluid property. (Compare to stirring.)

Modon: An equilibrium vortex pair, composed of an anticyclone and a cyclone in terms of pressure; for example, a warm-core ring and cold-core ring in the case of a baroclinic pair (Stern, 1975; Flier1, et. al., 1980). This ideal state is probably never reached for any length of time in the ocean; although, the basic principle is useful for considering vortex-vortex interactions.

North wa11 (of the Gulf Stream): The thermal front north (or west for latitudes below Cape Hatteras) of the Gulf Stream core. 
Overwash: The surface overriding of a feature with neighboring fluid. Distinguishable from streamer entrainment by the areal coverage of the feature which for overwash is typically on the scale of the ring.

Pigment: A measurement of the combined surface chlorophyll, phaeopigments and accessory pigments (fucoxyanthin, phycoerithryn, etco) which is used in conjunction with CZCS color fields. The satellite messurement is principally determined by the sum of the chlorophyll and chlorophyll degradation products-- phaeopigments. The accessory pigments are presumed to be a second order effect and are generally not considered.

Planetary vorticity: The component of vorticity derived from the rotation of the earth (see Pedlosky, 1979).

Potential vorticity: A conservative property of a fluid in the absence of dissipation or diabatic changes. In a warm-core ring this may be approximated as the absolute vorticity divided by the thickness of the fluid column: $(\zeta+f) / h$, where $\zeta$ is the relative vorticity, $f$ is the planetary vorticity, and $h$ is the thickness of the fluid column.

Radius of deformation: See Rossby deformation radius.

Relative vorticity: The sum of the angular momentum and the shear for a fluid flow (Batchelor, 1967) or for a ring (0180n, 1980).

Ring: Originally, those eddies which form as a result of the Gulf stream folding back upon itself thereby isolating a core of anomalous water inside a closed current of Gulf Stream water (Fuglister, 1972). Two types of Gulf Stream rings are possible and they are classified as a consequence of their formation location: rings formed in the Sargasso Sea have cold (Slope Water) cores and rotate cyclonically; whereas, rings formed in the slope Water have warm (Sargasso Sea) cores and rotate anticyclonically. More recent $1 \mathrm{y}$, the term is applied to eddies formed from other western boundary currents in a similar fashion. The functional feature is the existence of a high velocity jet or front around the eddy and the ability of the eddy to transport fluid properties with it as it translates.

Ring center: Various descriptions of ring center are, of course, possible. The two most common are the Eulerian center, which is calculated from the center of mass of an isotherm anomaly, and the Lagrangian center, which is usually calculated from drifter trajectories (see Flier1, 1981; Hooker, 1983)

Ring core: The water trapped within the region of the ring which carries anomalous water properties with respect to the far field reference.

Ring phase: By convention, the orientation of the major axis with respect to true north. 
Ring translation: The motion of the center of mass of a ring; this is preferred over propagation, since it does not connotate strict wave-like behavior.

Rossby deformation radius: The distance over which the gravitational tendency to render a free surface $f$ lat is balanced by the tendency of the Coriolis acceleration to deform the surface (Pedlosky, 1979).

Seasonal thermocline: A region in the upper water column where temperature changes rapidly with depth. Seasonal thermoclines are not a permament feature of a water column and are usually formed as a consequence of the annual warming associated with the summer season (compare with thermocline).

Sea Surface Temperature (SST): A measure of the temperature of the ocean's surface usually made with a bucket from water just below the surface, or a continuously recording system taking water from $3-5 \mathrm{~m}$ below the surface, or an average value from the upper 1-5 m observed by CTD or XBT. (Not to be confused with skin temperature)

Shelf water: Those waters formed over the continental shelves; that is, water to depths of 200 meters or less.

Shingle: See spin-off eddy.

Skin temperature: The radiation temperature of the upper milimeter of the ocean sensed by satellite (AVHRR or CZCS). (See also sea surface temperature.)

Slope Water: A mixture of one-third Gulf Stream water and two-thirds Shelf water ( $\mathrm{McCl}$ ellan, 1959). The actual mixture varies in agreement with the region's nature as a transition zone between high latitude waters and the waters of the subtropical gyre (Wright, 1978).

Spin-off eddy: A highly anisotropic ageostrophic eddy associated with intense fronts, like the Gulf Stream or rings, less than one deformation radius across (approximately 10-30 kilometers) but of varying length (up to 100 $\mathrm{km}$ or more). They are also known as shingles and if found on the north wall of the Gulf Stream, they usually have cyclonic circulations.

SST: See Sea Surface Temperature.

Stirring: The production of property gradients by the straining and shearing of water masses. When property gradients become sufficiently large molecular diffusion acts to remove these gradients and promote homogeneous (mixed) properties. (See also mixing.)

Streamer: A strong advective feature delineated by sharp frontal boundaries or edges whose along track dimension greatly exceeds the across track dimension.

Swirl velocity: The azimuthal current in a vortex. 
Thermocline: The deep region in a water column where temperature changes rapidly with depth. Also known as the permanent thermocline because of the absence of seasonal variability.

Thermostad: A region of low vertical temperature gradient usually consisting of homogeneous properties; e.g., salinity. A warm-core ring's thermostad is most often modified central water from the Sargasso Sea.

Trapped zone (or region): The volume of fluid moving with a ring; i.e., the ring core (see Flier 1, 1981).

Turbulent diffusion: Macroscale analog to molecular diffusion. The effective down-gradient transport of a property by turbulent motions.

Vortex: An isolateable component of a flow field that has a closed circulation of its own. Note that for a weak vortex the net flow may carry fluid through the feature. 


\section{References}

Batchelor, G. K. 1967. An Introduction to Fluid Mechanics. Cambridge, Pres8, 615 pp.

Flierl, G. R. 1981. Particle motions in large-amplitude wave fields. Geophys. Astrophys. Fluid Dyn., $18: 39-74$.

Flierl, G. R., V. D. Kamenkovich, J. C. Williams, and G. N. Reznick. 1980. The dynamics of baroclinic and barotropic solitary eddies. Dyn. Atmos. Oceans, 5: 1-41.

Fuglister, F.C. 1972. Cyclonic rings formed by the Gulf Stream, 1965-66. In: Studies in Physical Oceanography $=$ A Tribute to Georg Wust on His 80 th Birthday. A. L. Gordon, ed., Gordon and Breach, 1: 137-168.

Gordon, H. R., and W. R. McCluney. 1975. Estimation of the depth of sunlight penetration in the sea for remote sensing. Applied Optics, 14: 413-416.

Hooker, S. B. 1983. Ring center determination and its application to ring sampling strategies, ring translation and Gulf Stream ring wakes. M.S. Thesis, University of Miami, $91 \mathrm{pp}$.

McClellan, H. J. (1959). On the distinctness and origin of the slope Water off the Scotial Shelf and its easterly flow south of the Grand Banks. J. Fish. Res. Board Can. 14: 213-239.

01 son, D. B. 1980. The physical oceanography of two rings observed by the cyclonic ring experiment: Part II. Dynamics. J. Phys. Oceanogr., 10 : $514-528$.

Parsons, T., M. Tukahashi, and B. Hargrave. 1977. Biological Oceanographic Processes, Pergamon Press, 332 pp.

Pedlosky, J. 1979. Geophysical Fluid Dynamics, Springer-Verlag, $624 \mathrm{pp}$.

Reid, R. O., B. E. Elliott, and D. B. Olson. 1981. Available potential energy: a clarification. Geophys. Res. Letters, 3(10): 625-628.

Smith, R.C. 1981. Remote sensing and depth distribution of ocean chlorophy11. Marine Ecology Prog. Series 5: 359-361.

Smith, R. C. and K. S. Baker. 1978. The bio-optical state of ocean waters and remote sensing. Limnol. Oceanogr., 23(2): 247-259.

Smith, R. C., K. S. Baker, and P. Dustan. 1981. Fluorometric techniques for the measurement of oceanic chlorophyll in the support of remote sensing. Scripps Institution of Oceanography, SIO Ref. 81-17, La Jolla, California 92093. 
Stern, M. E. 1975. Minimal properties of planetary eddies. J. Mar, Res, $33(1): 1-13$.

Stomme1, H. 1966. The Gulf Stream, 2nd edition, Univ. of California Press, $248 \mathrm{pp}$.

Wright, W. R. 1978. Physical Oceanography. Chapter 4. In: Summary of Environmental Information of the Continental Slope - Canadian United States Border to Cape Hatteras, North Carolina. Submitted to the Bureau of Land Management, Marine Minerals Div., by Research Institute of the Gulf of Maine (TRIGOM), South Portland, Maine, 110 pp. 


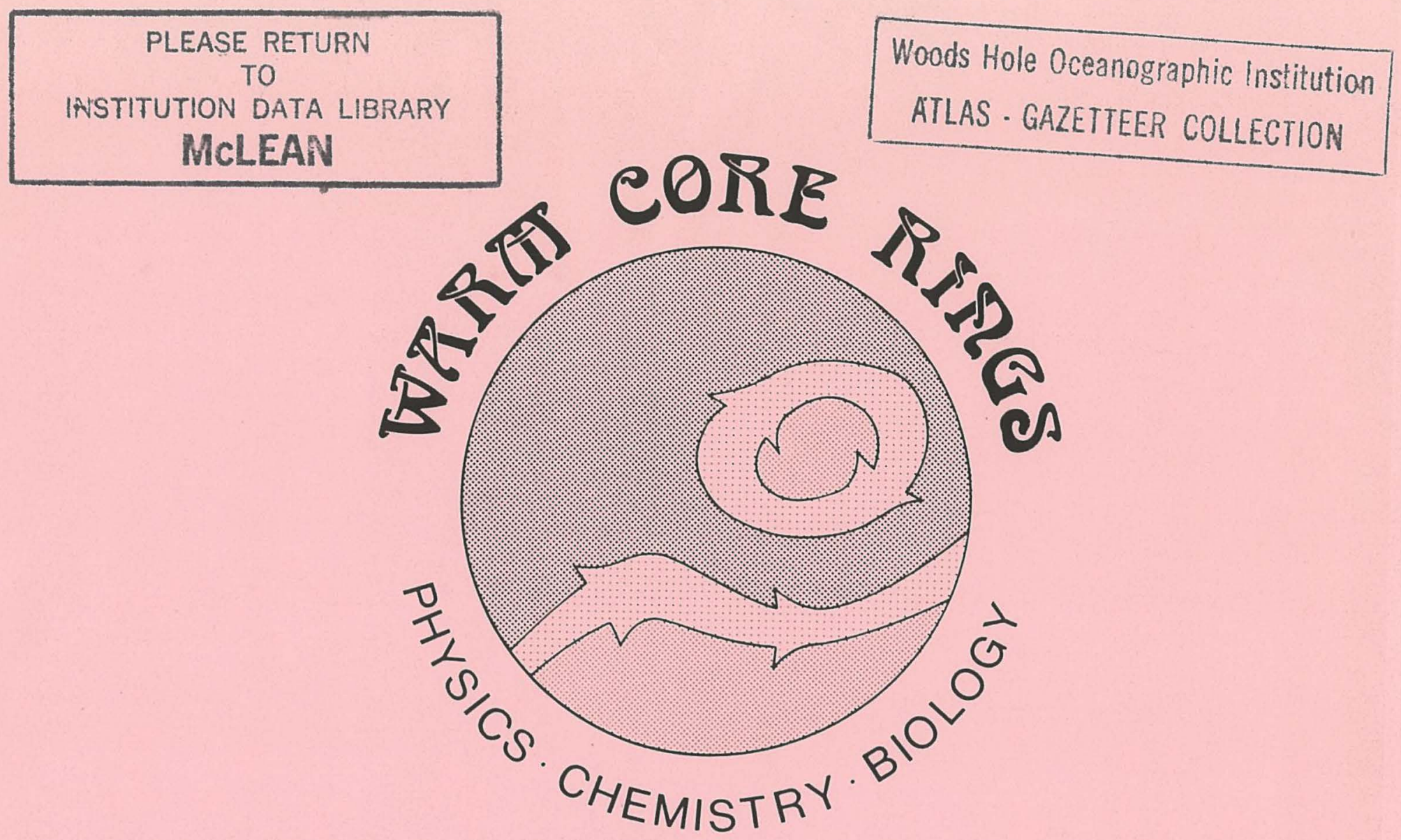

SATELLITE IMAGES OF WARM-CORE RING 82-B 

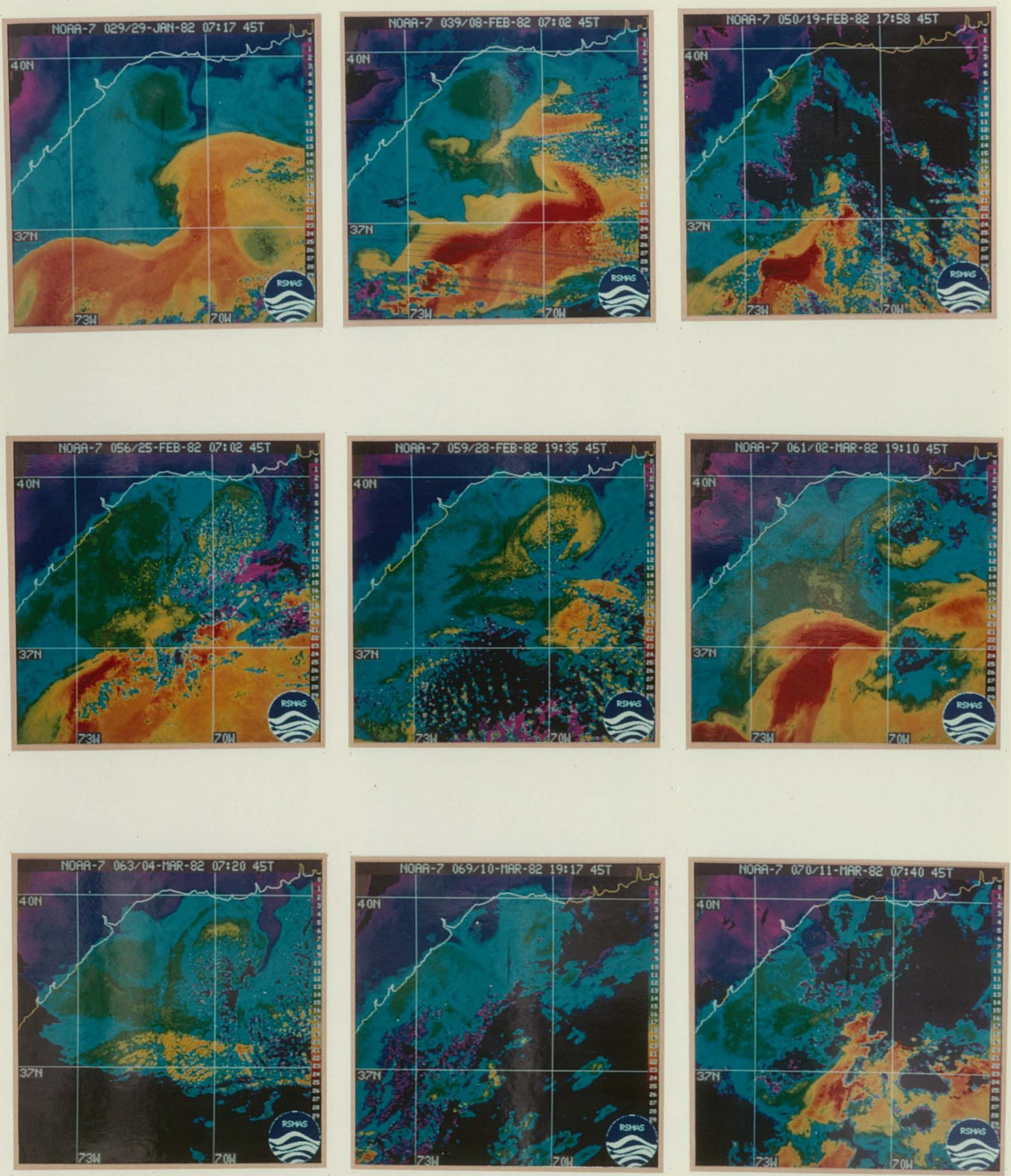

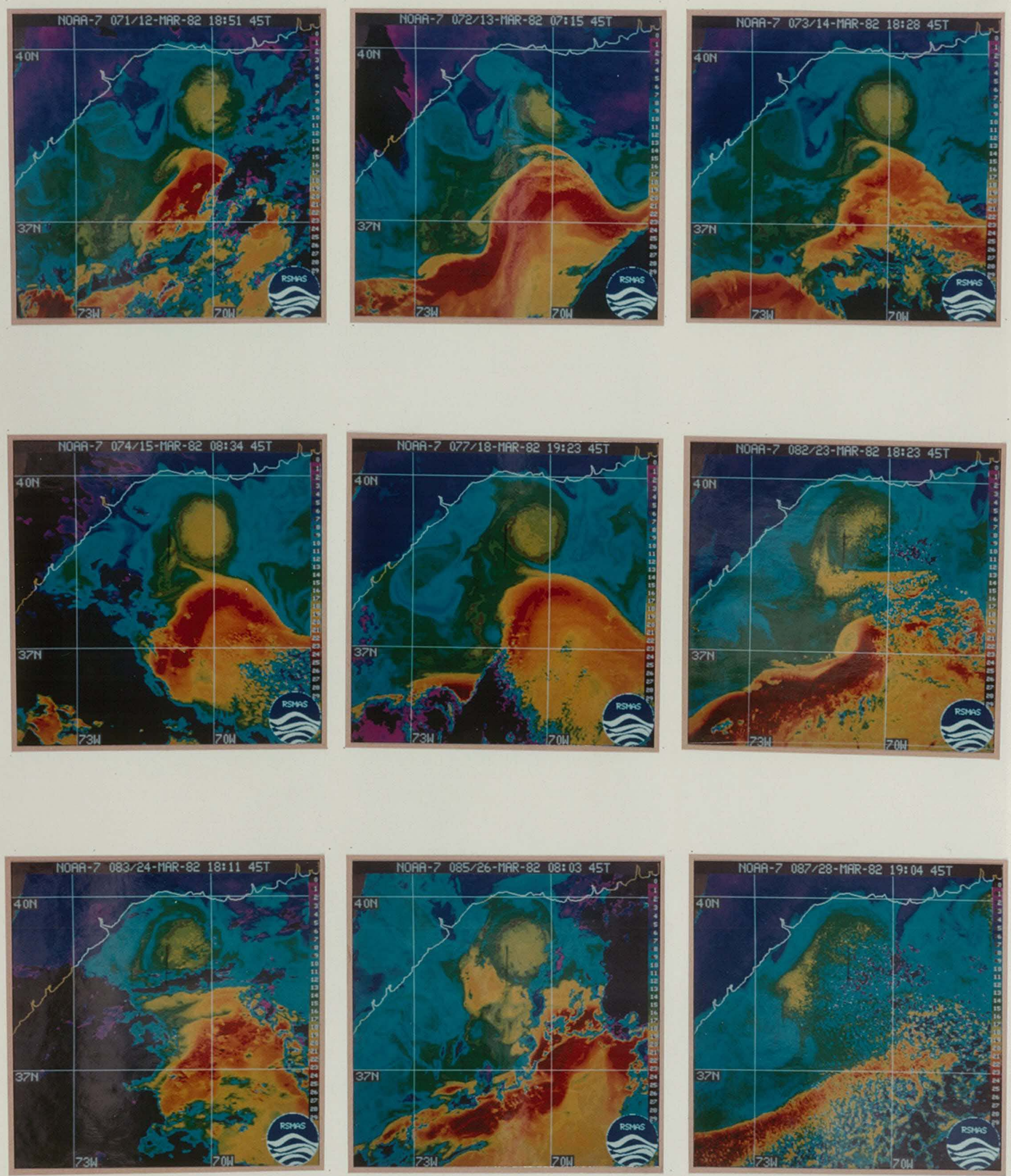

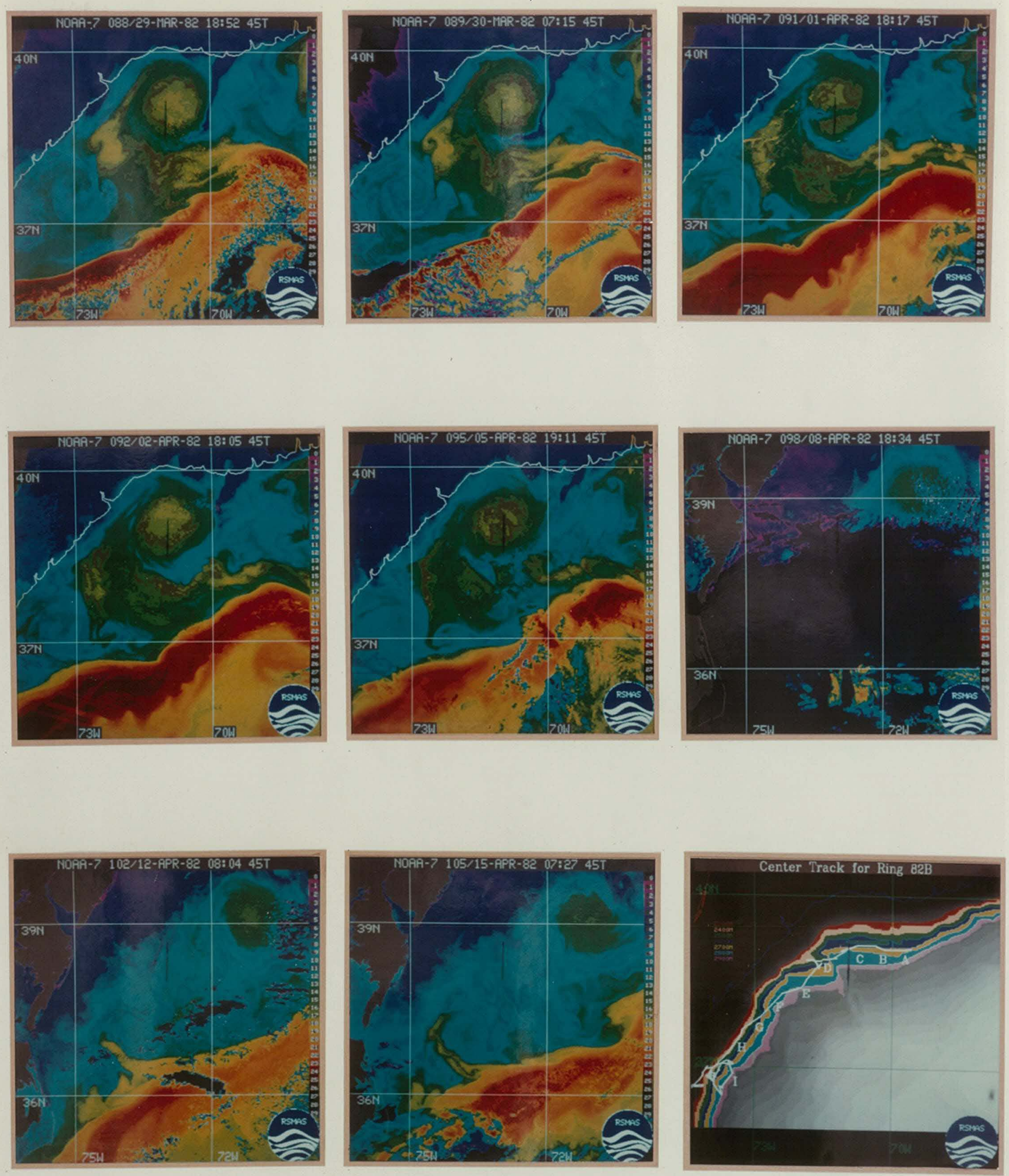

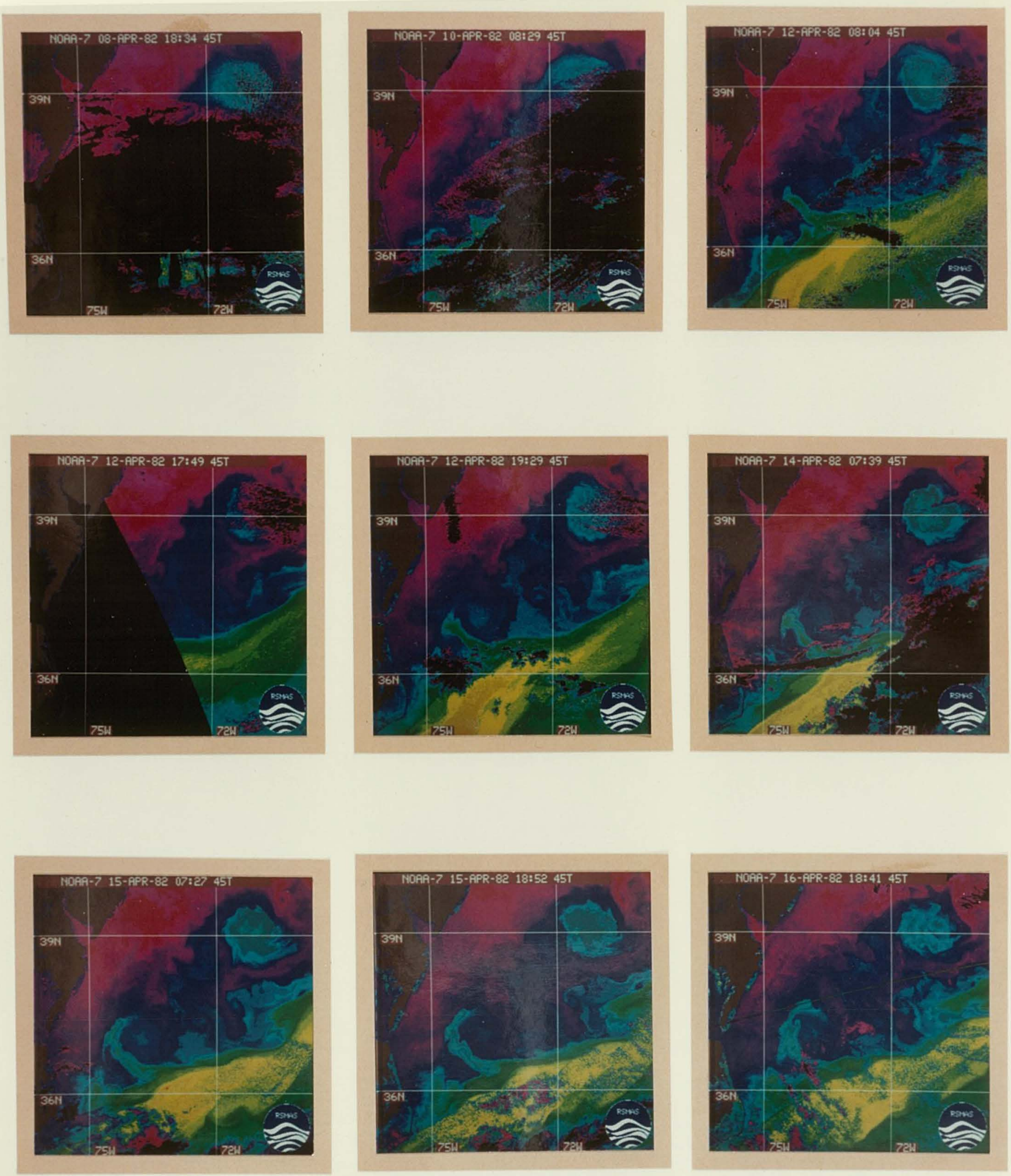

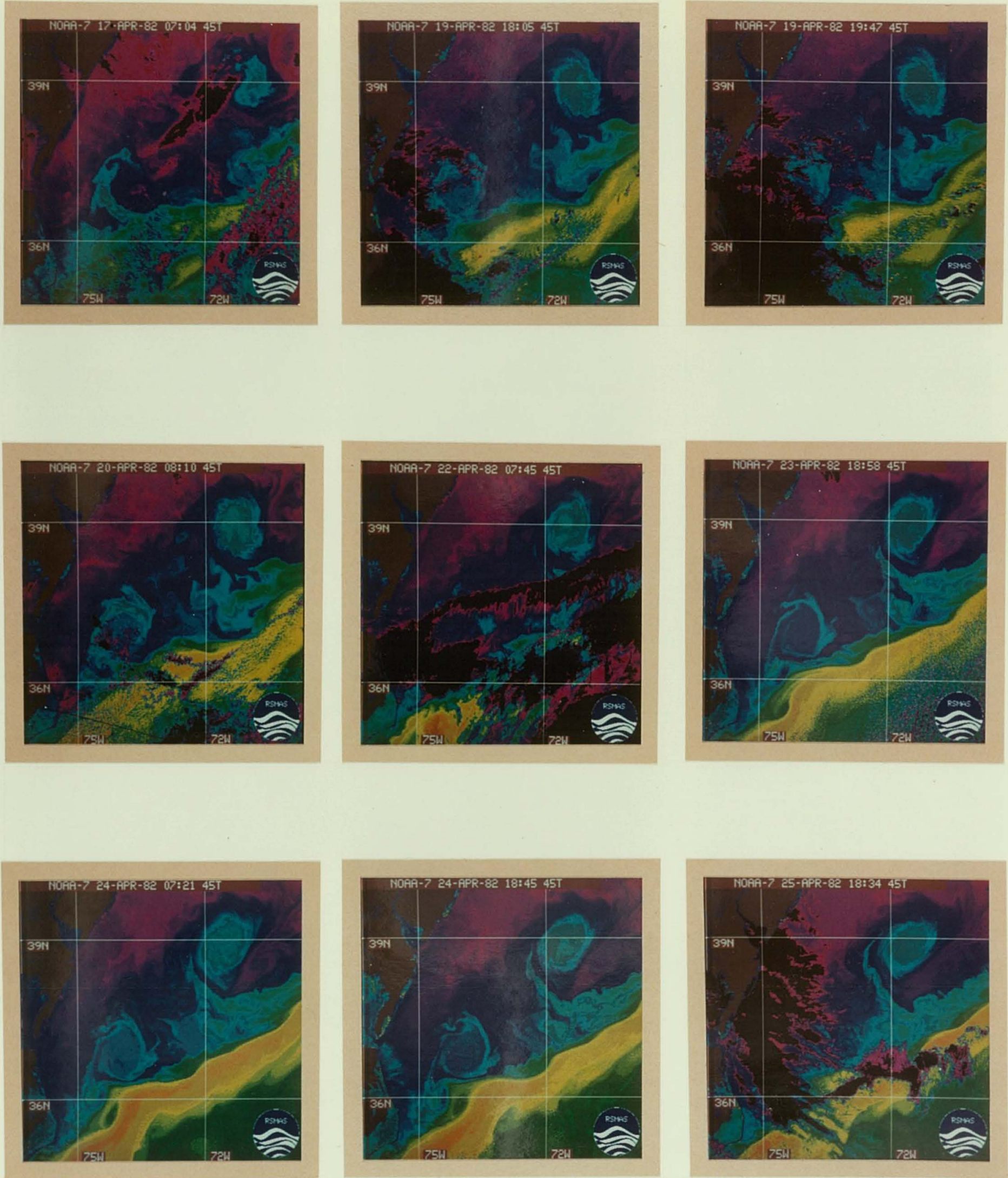

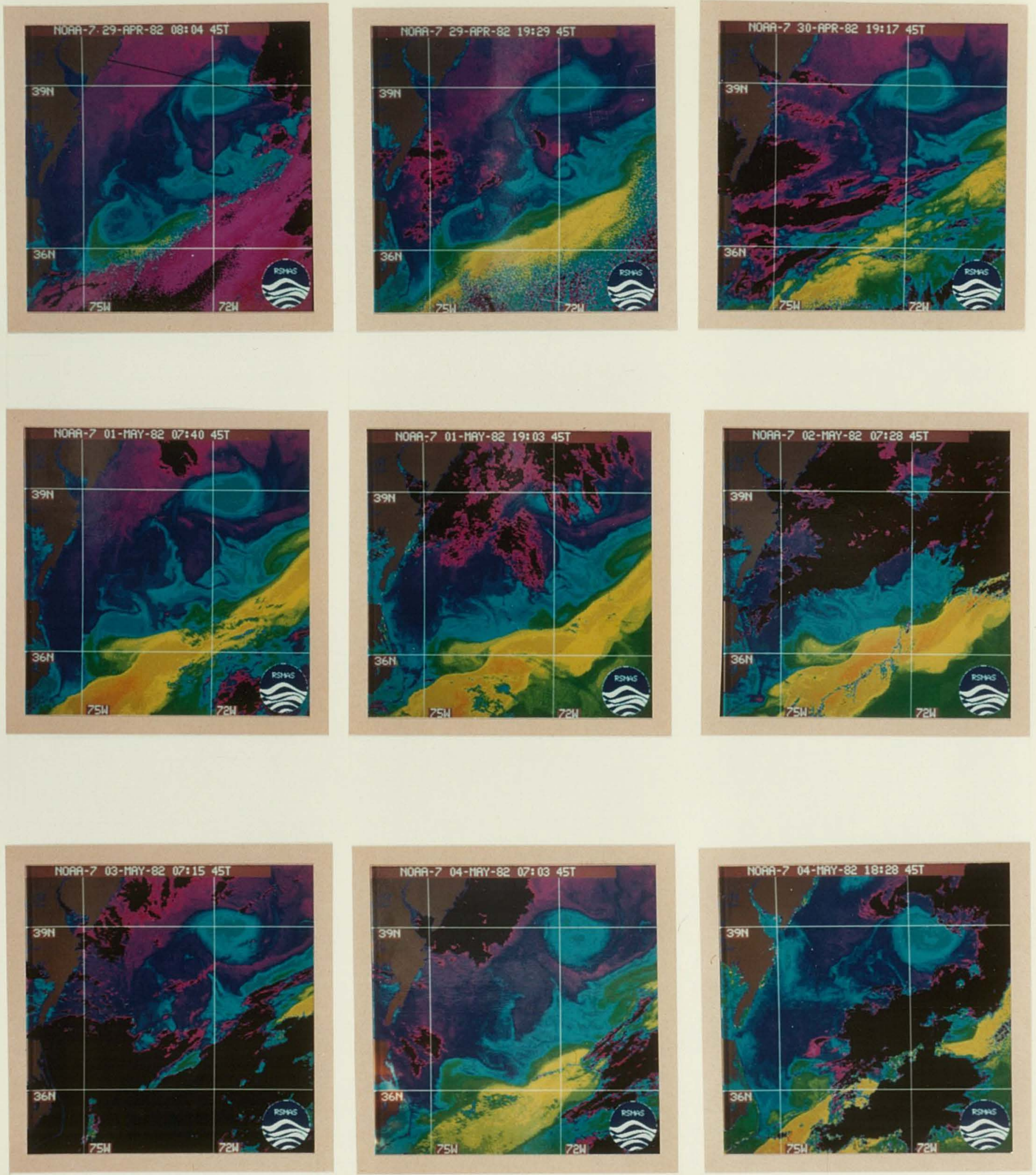

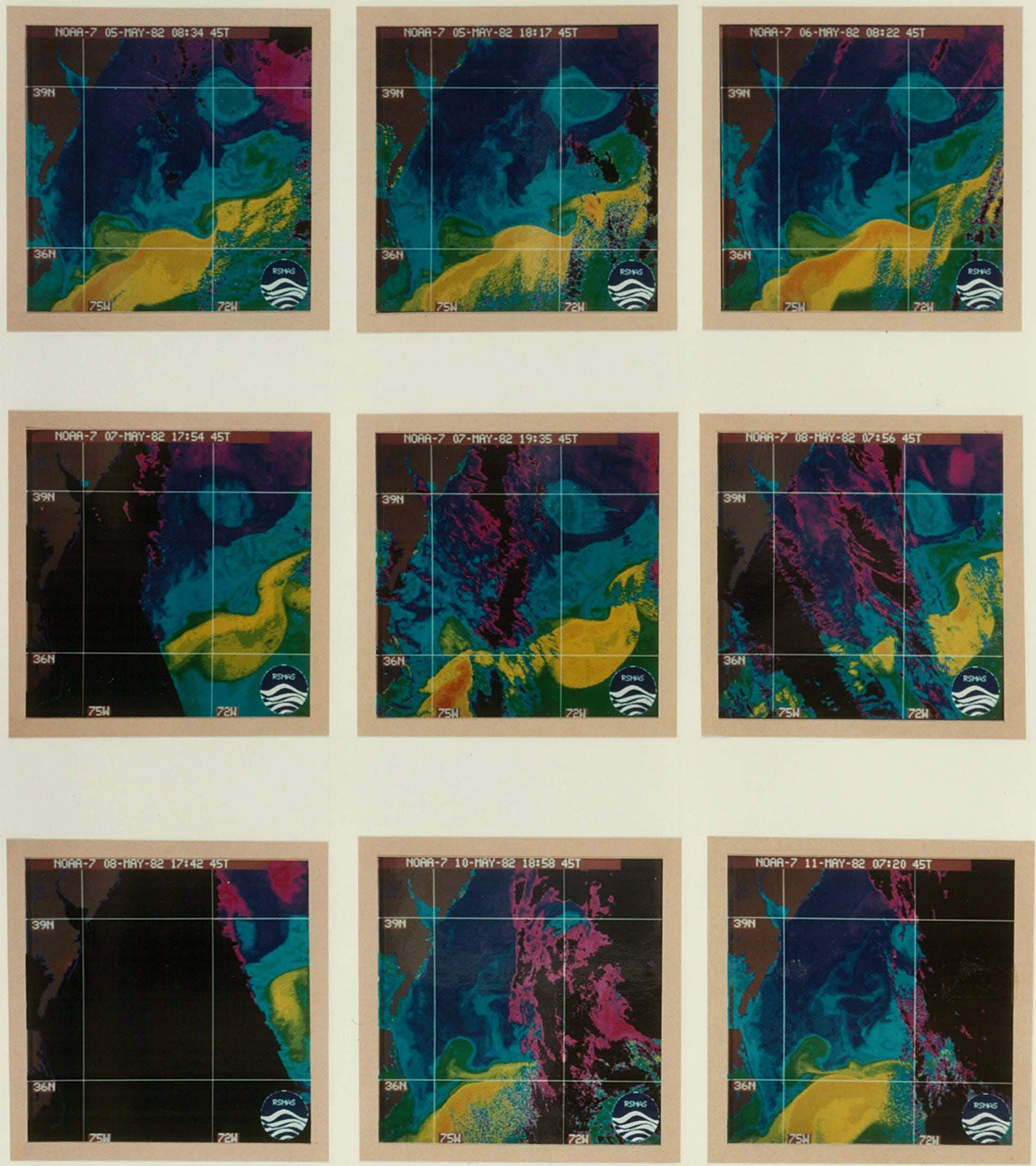

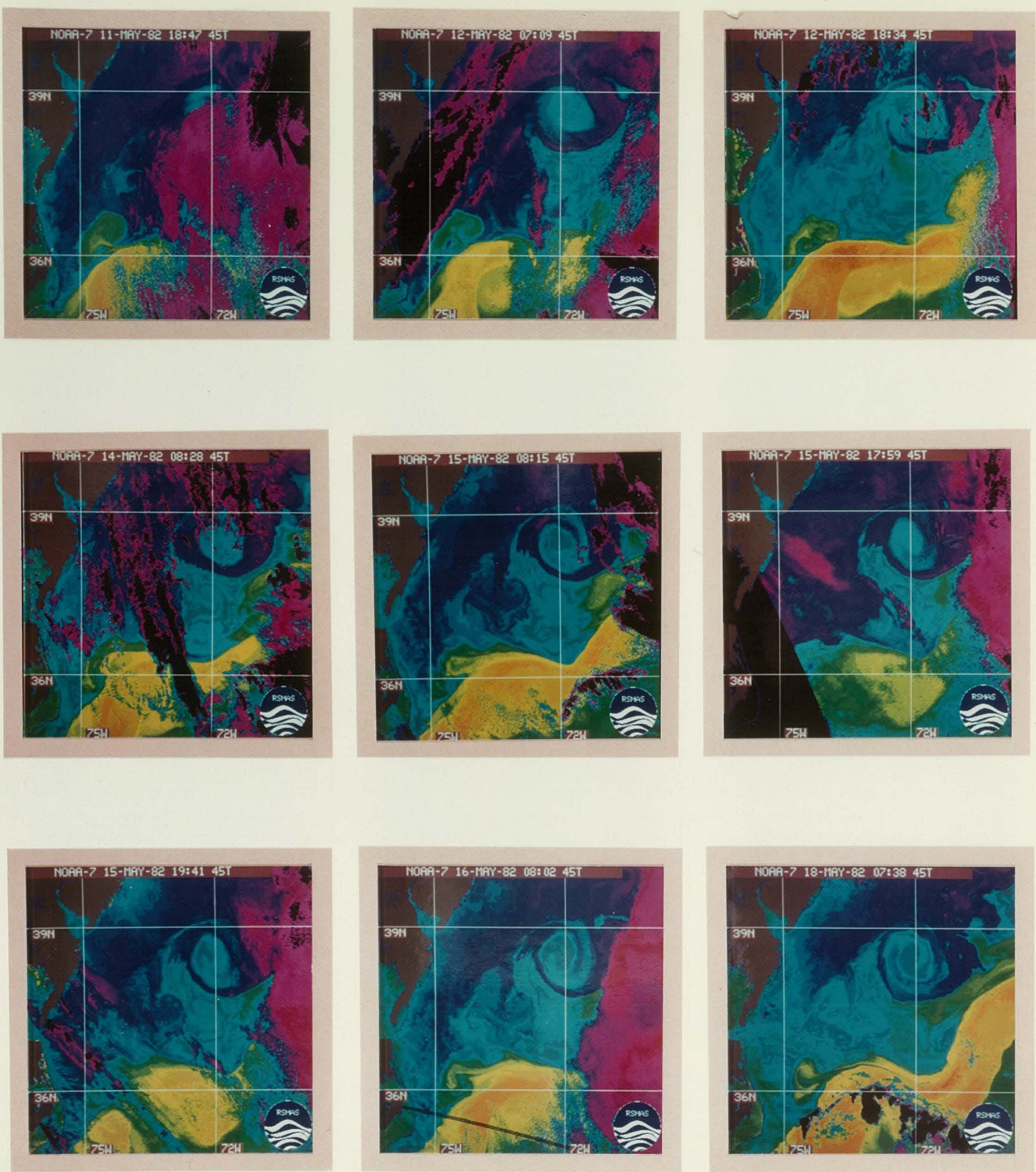

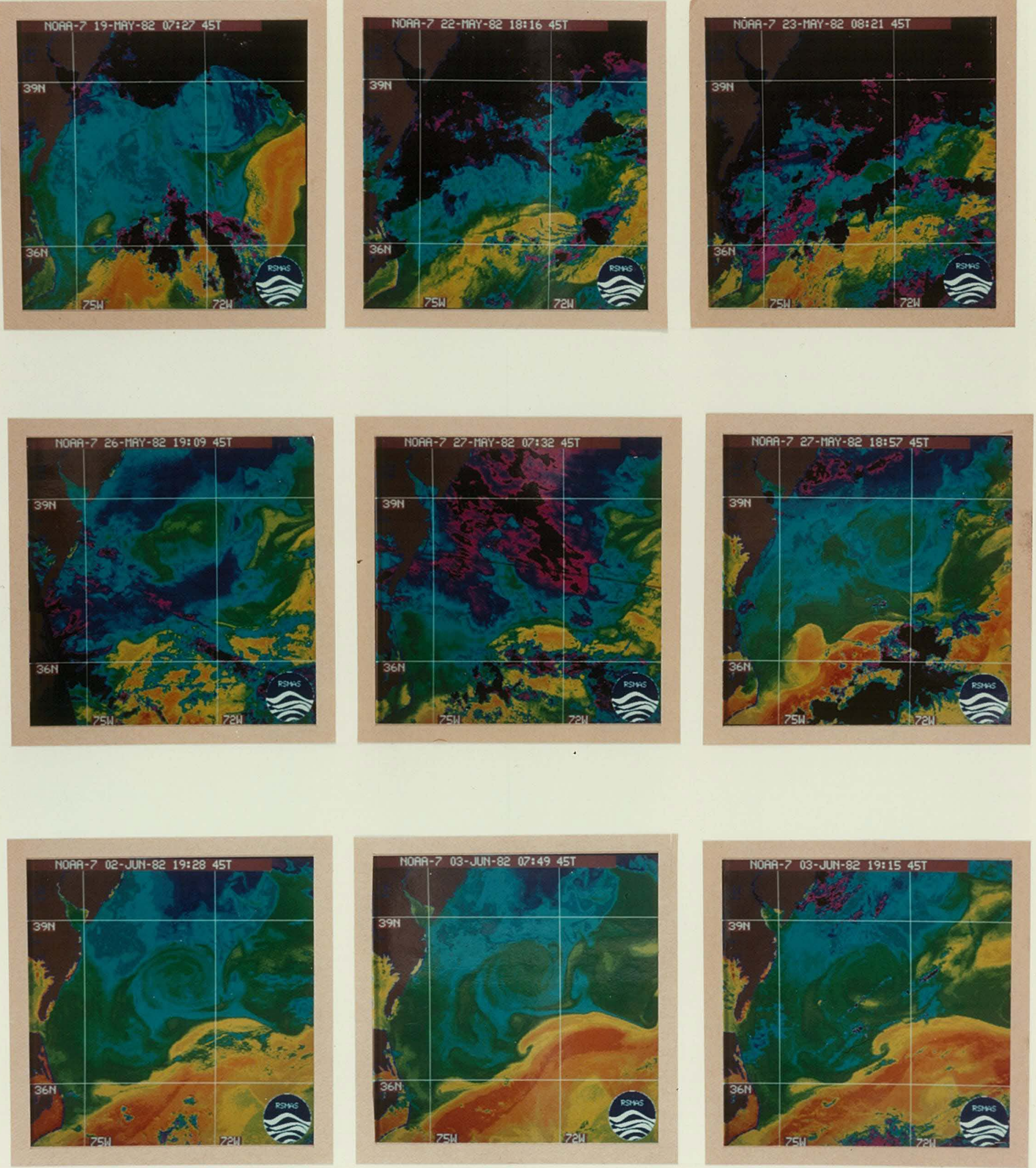

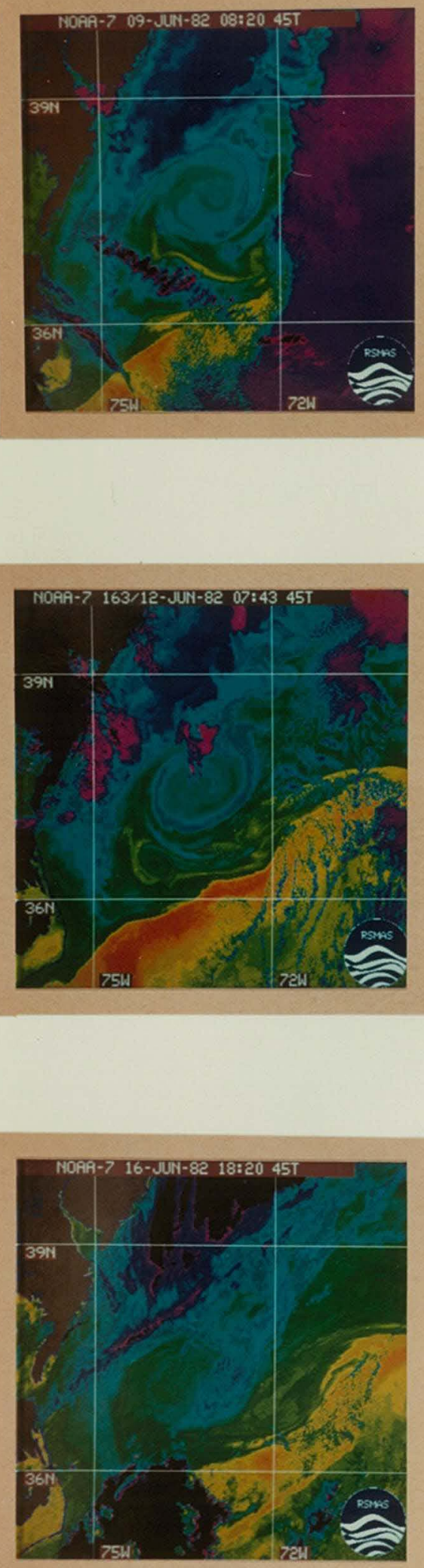
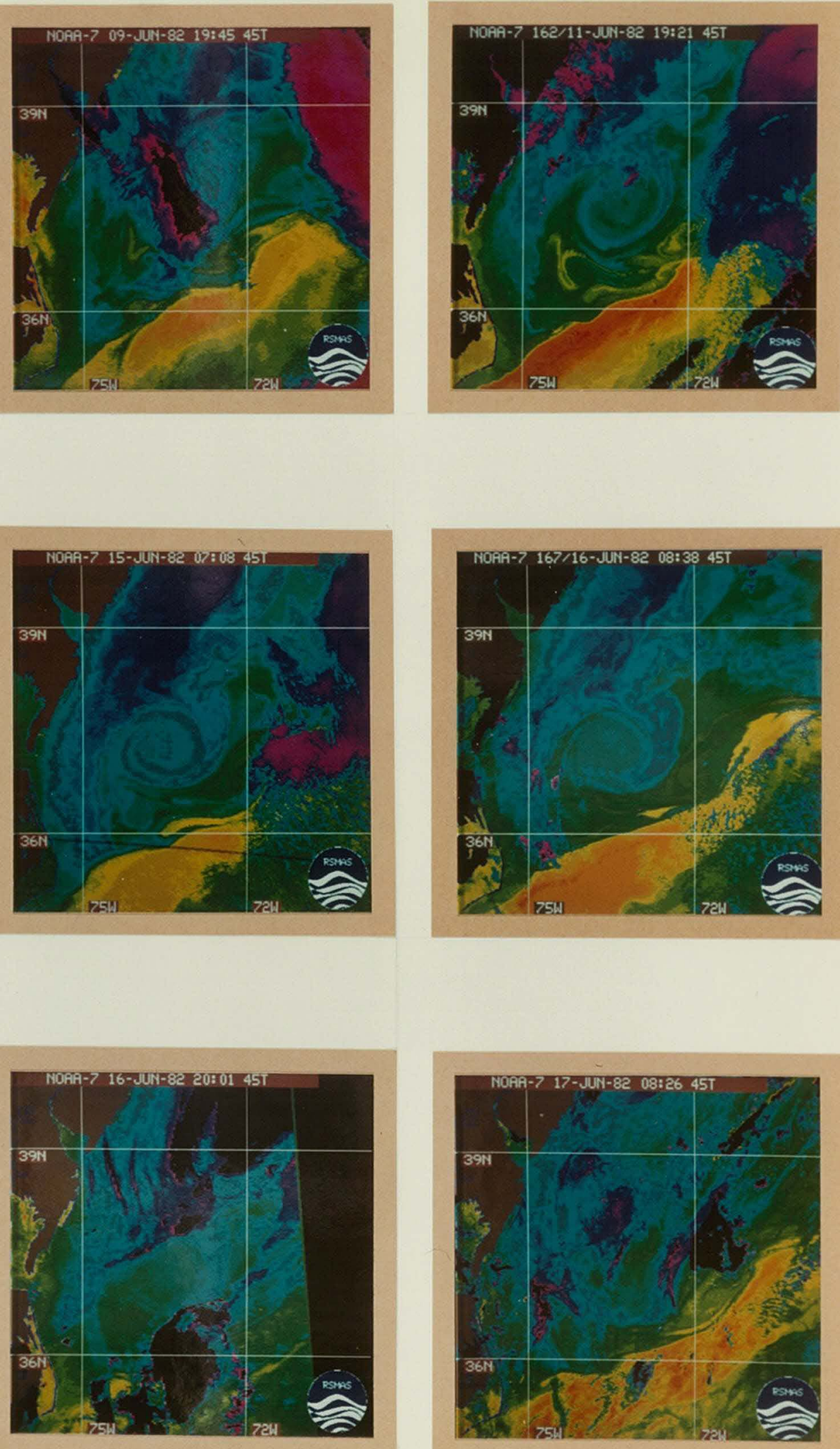

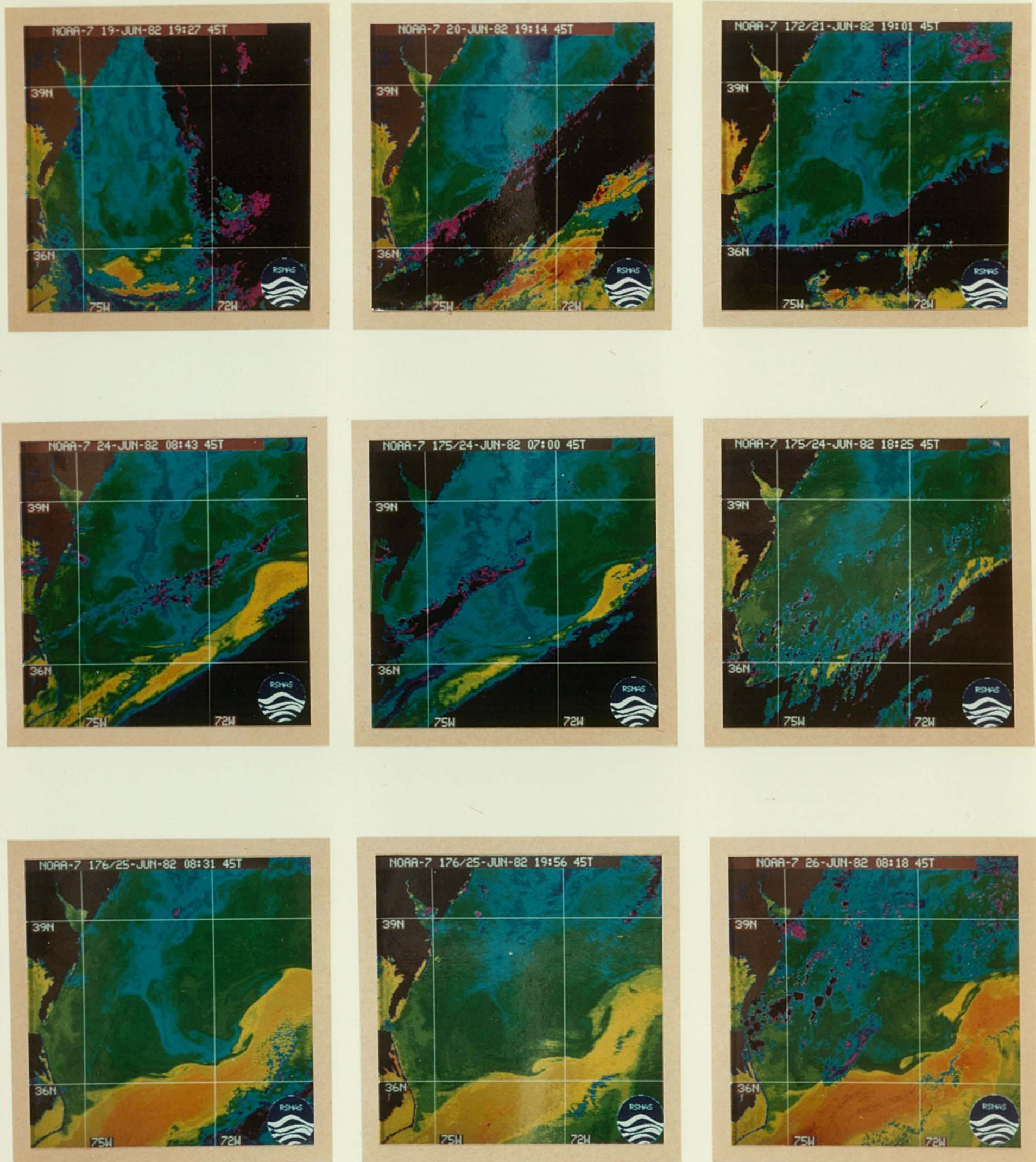

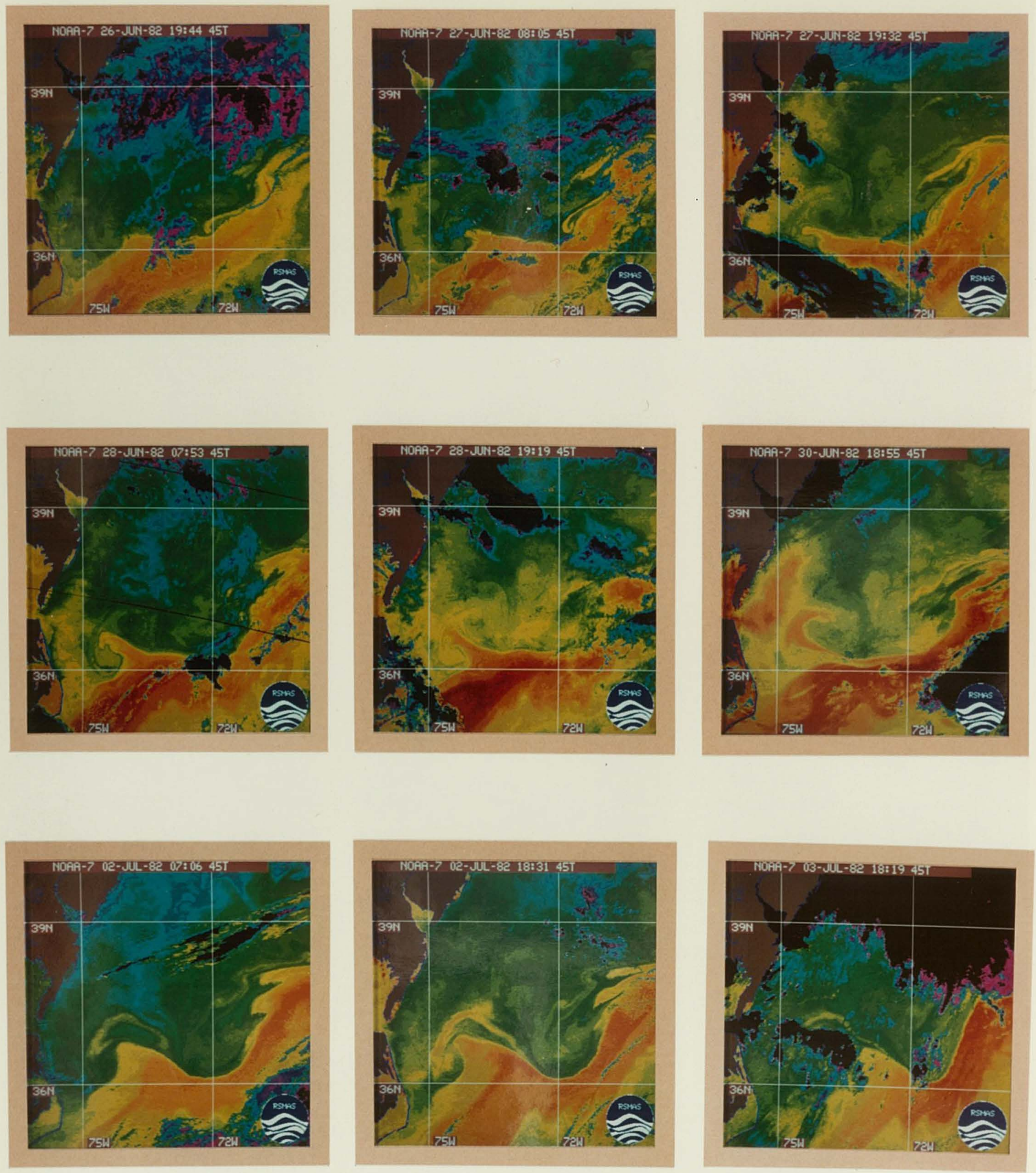

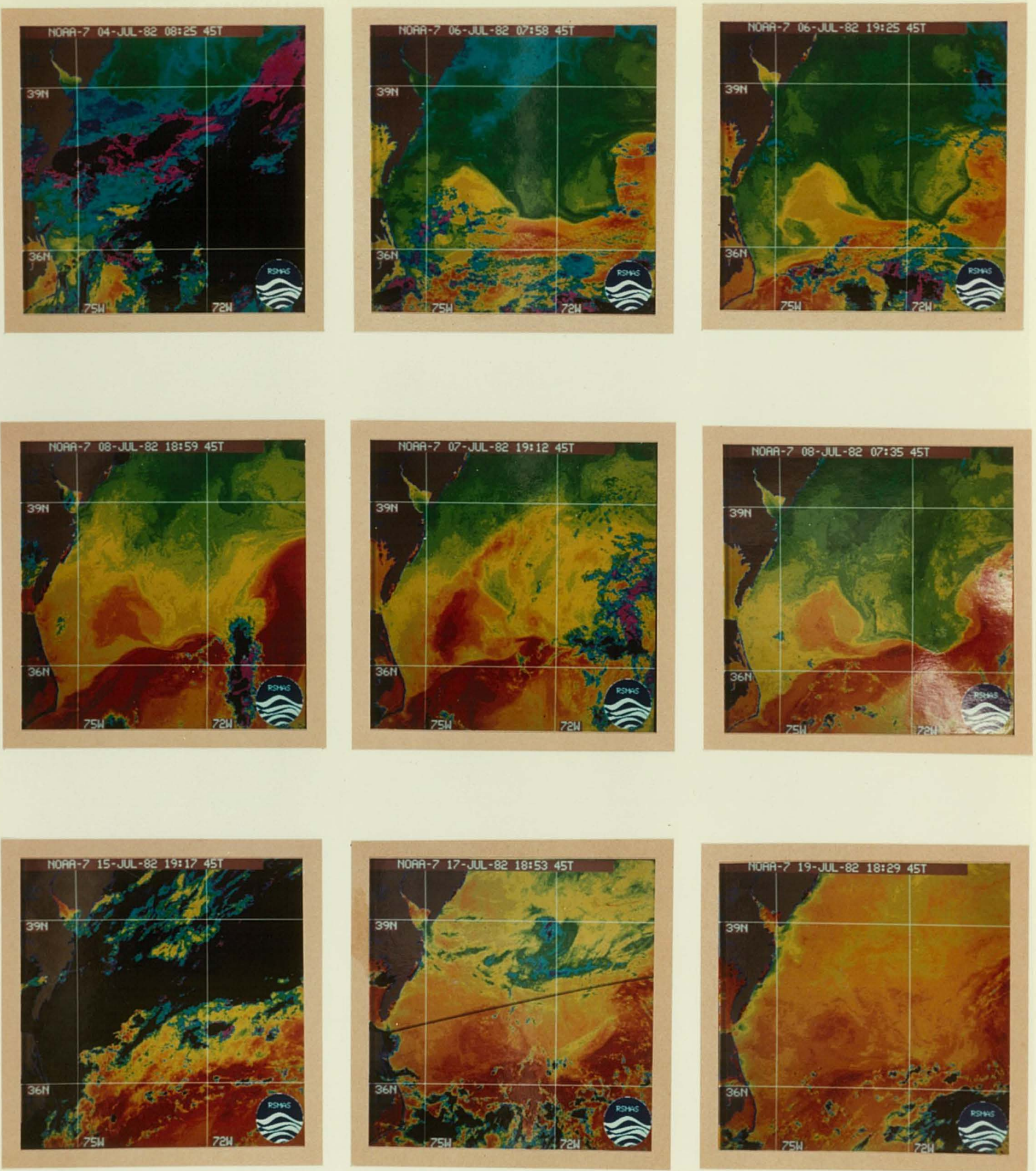

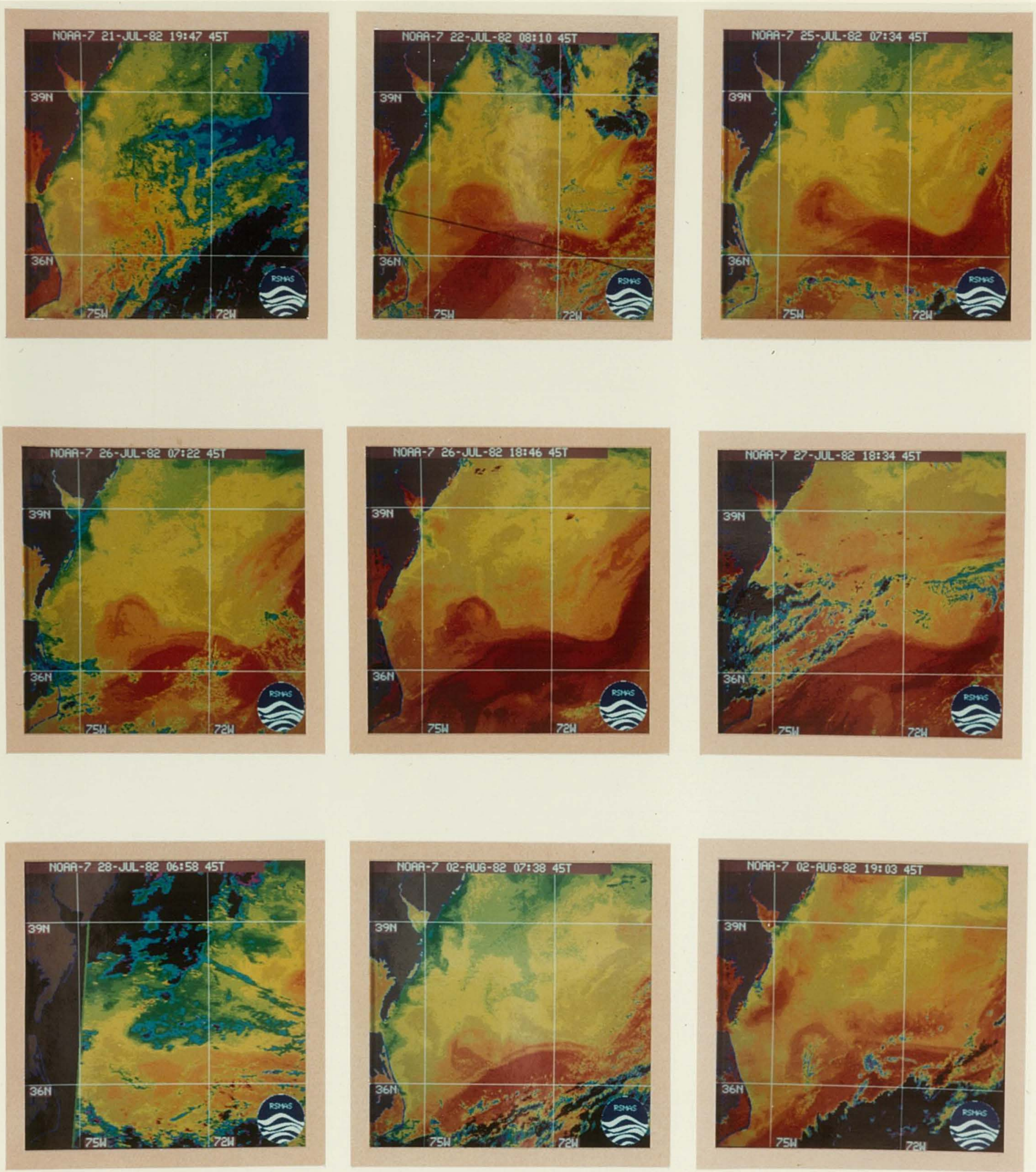

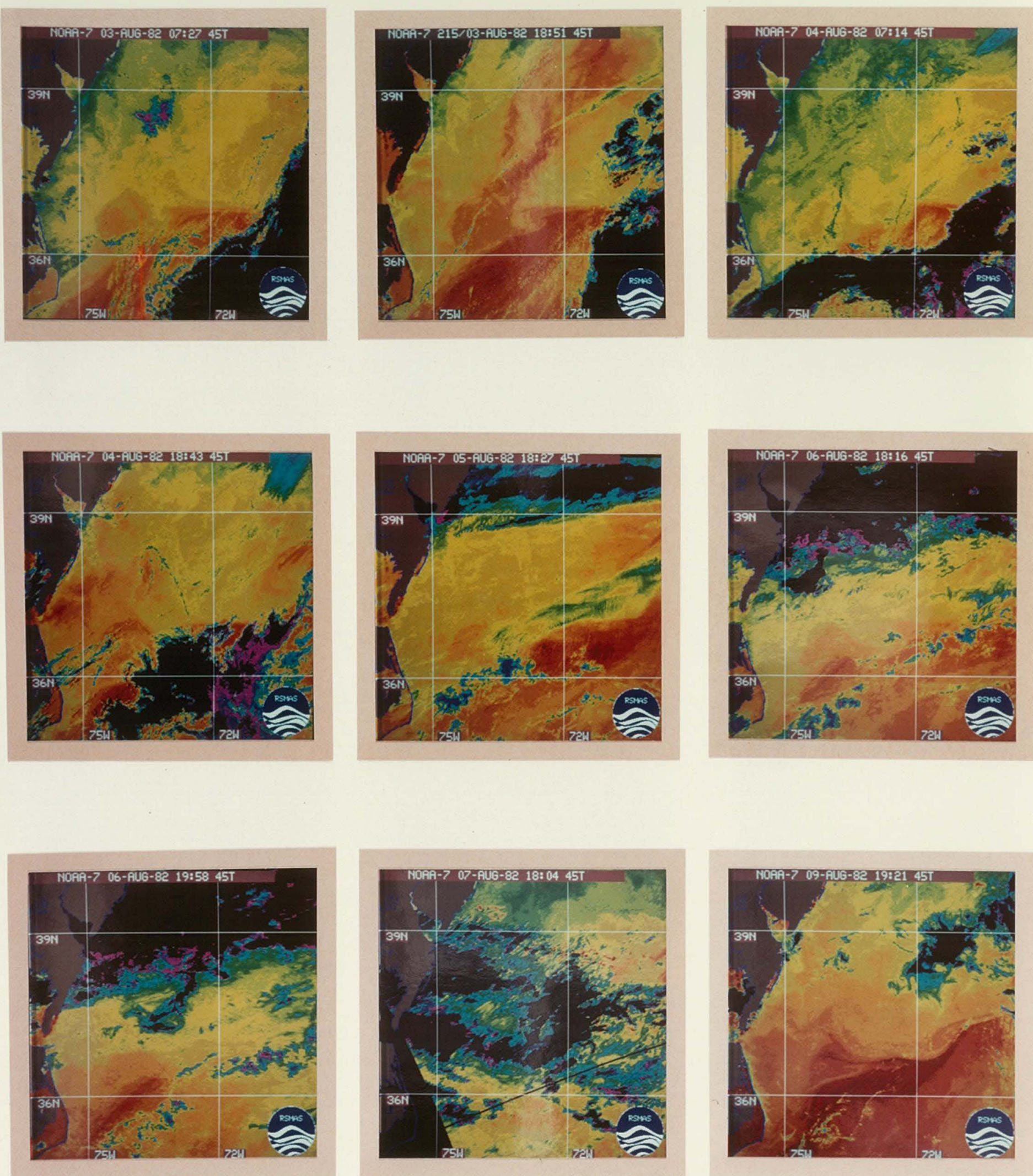

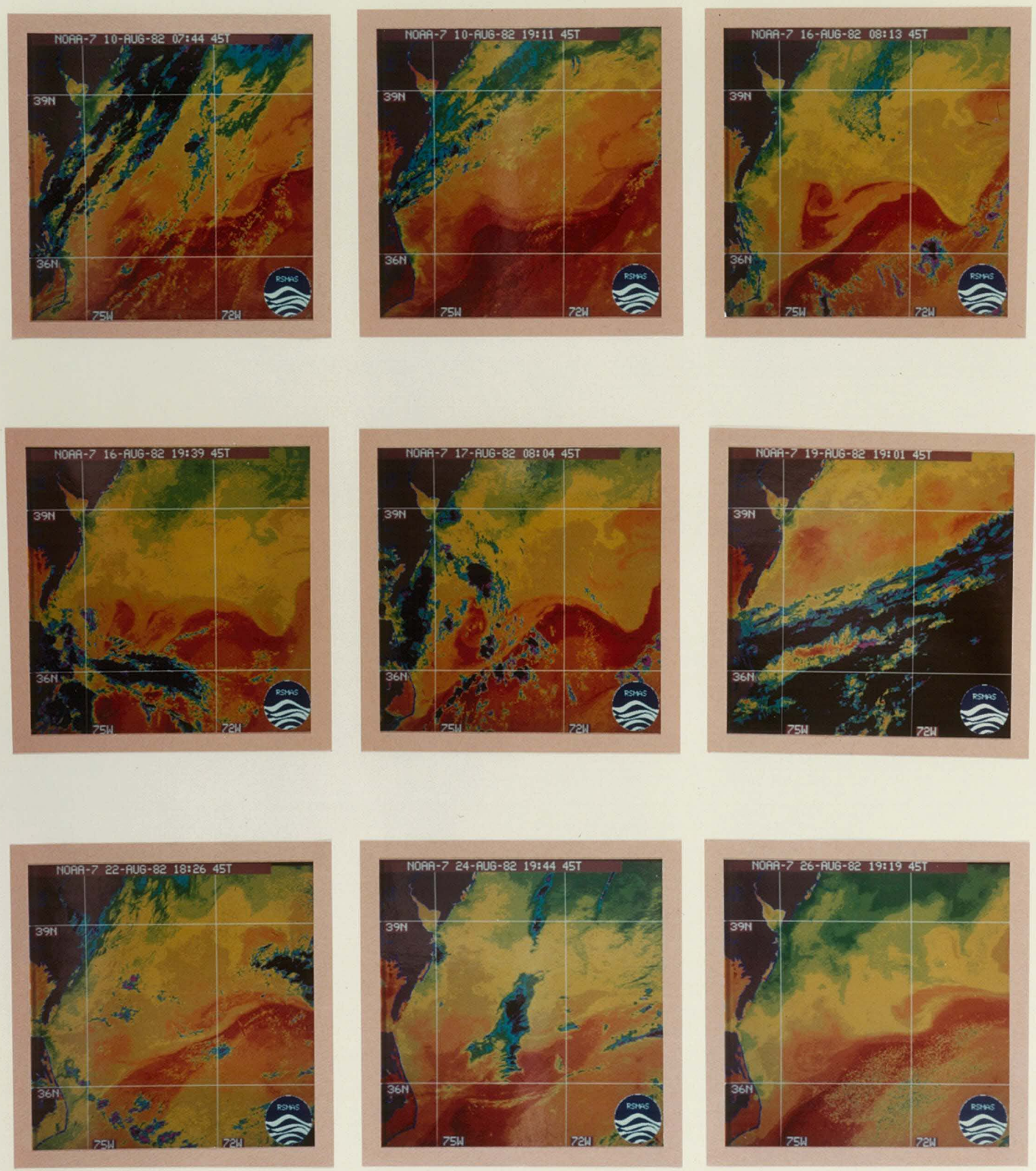

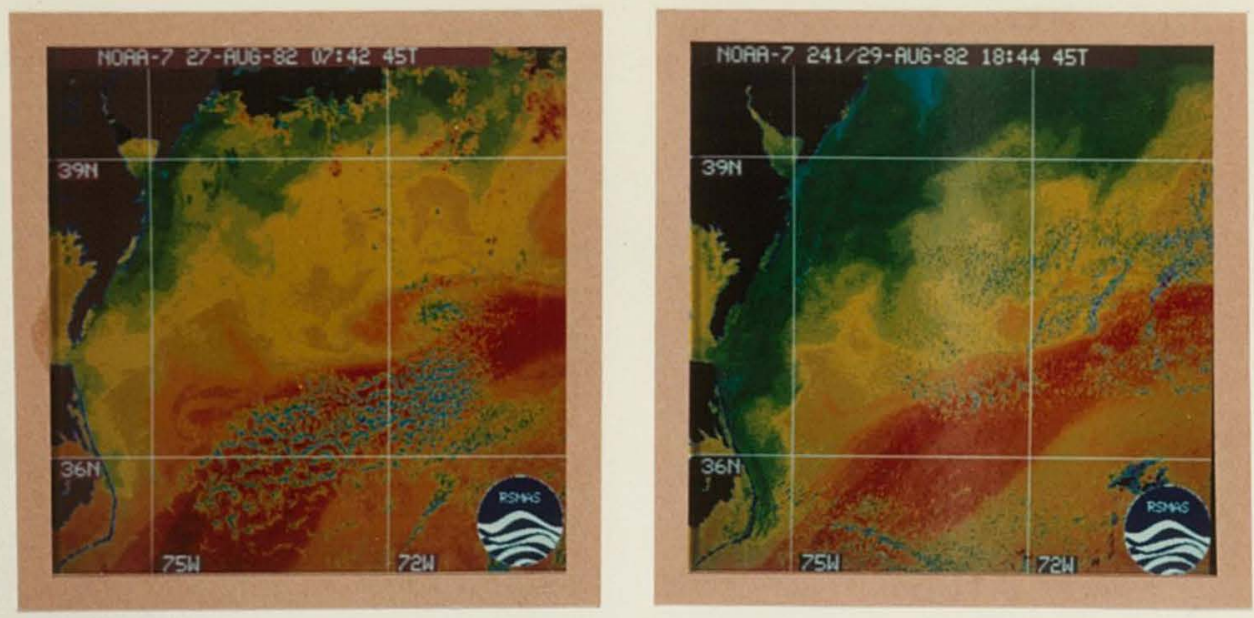


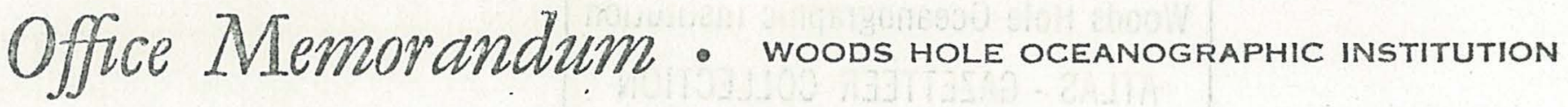

To : Al Morton

DATE: April 5, 1984

From : William Dunkle

SUBjECr: Satellite Imagery Booklet

Please charge account 5318 with $\$ 46.50$ for the purchase of a satellite imagery booklet from the Warm Core Rings Project Office.

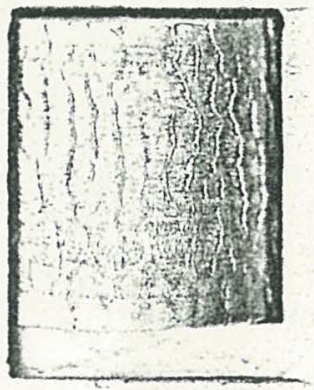

